The University of San Francisco

USF Scholarship: a digital repository @ Gleeson Library |

Geschke Center

Business Analytics and Information Systems

School of Management

February 2013

\title{
Work System Theory: Overview of Core Concepts, Extensions, and Challenges for the Future
}

Steven Alter

University of San Francisco, alter@usfca.edu

Follow this and additional works at: http://repository.usfca.edu/at

Part of the Business Administration, Management, and Operations Commons, Management $\underline{\text { Information Systems Commons, and the Technology and Innovation Commons }}$

\section{Recommended Citation}

Alter, Steven, "Work System Theory: Overview of Core Concepts, Extensions, and Challenges for the Future" (2013). Business Analytics and Information Systems. Paper 35.

http://repository.usfca.edu/at/35

This Article is brought to you for free and open access by the School of Management at USF Scholarship: a digital repository @ Gleeson Library | Geschke Center. It has been accepted for inclusion in Business Analytics and Information Systems by an authorized administrator of USF Scholarship: a digital repository @ Gleeson Library | Geschke Center. For more information, please contact repository@usfca.edu. 


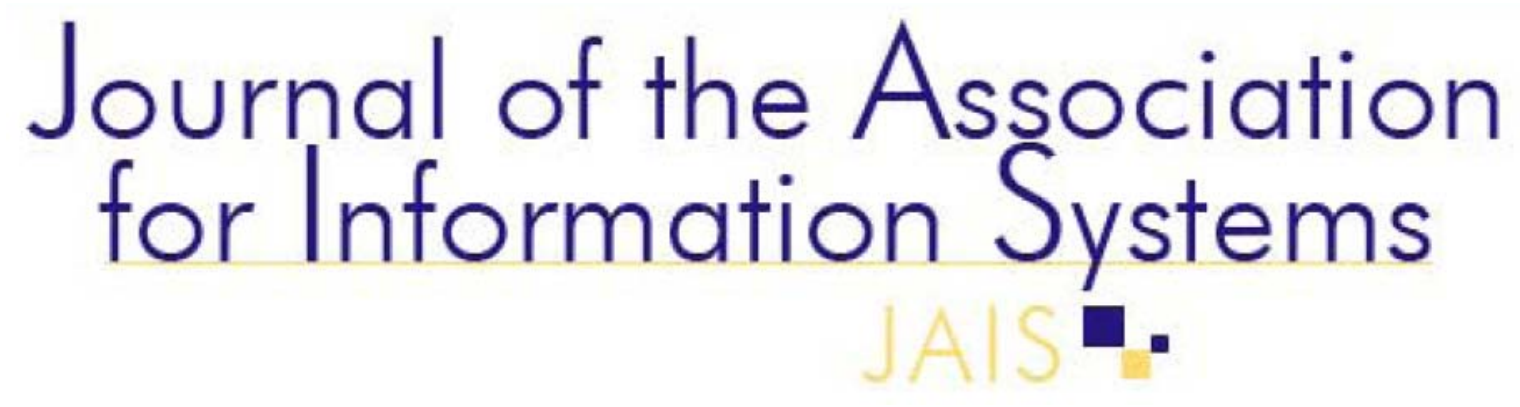

Research Article

\title{
Work System Theory: Ovenview of Core Concepts, Extensions, and Challenges for the Future
}

\author{
Steven Alter \\ University of San Francisco \\ alter@usfca.edu
}

\begin{abstract}
This paper presents a current, accessible, and overarching view of work system theory. WST is the core of an integrated body of theory that emerged from a long-tem research project to develop a systems analysis and design method for business professionals called the work system method (WSM). After discussing WST's basic premises and its two central frameworks, this paper summarizes the relationship between WST and WSM. It shows how experience with early versions of WSM led to three extensions of WST that addressed limitations-inuse in one of the central frameworks in WST. After comparisons with related theories, this paper closes with an evaluation of progress to date, new directions for resea rch related to WST, and implications for the IS discipline. The two appendices summarize the long tem research from which WST emerged and use a positioning map to show how WST is related to other topics in the IS discipline.
\end{abstract}

Keywords: Work System, Work System Framework, Work System Life Cycle Model, Theory in IS.

* Shirley Gregor was the accepting senior editor. This artic le wa s submitted on 315t Ma rch 2011 and went through two revisions. 


\section{Work System Theory: Overview of Core Concepts, Extensions, and Challenges for the Future}

\section{Need for an Alternative View of Systems}

The fundamental term "system" is problematic in the IS discipline. A former editor-in-chief of MIS Quarterly said that "It is no exaggeration to describe most IS researchers as having used the term 'system' or 'systems' to refer to just about anything that involves electronic information processing" (Lee, 2010, p. 339). He continues: "The conflict between the information system discipline's espoused theory of itself as a systems discipline and its theory-in-use of itself as a non-systems discipline has the obvious detrimental consequence in which much information systems research does not qualify as truly information systems research" (p. 341). Along similar lines, Alter (2004a) distinguishes between tool thinking and system thinking in the IS discipline and argues that more system thinking is needed.

While systems analysis and design textbooks certainly recognize the importance of broader systems in which IT is applied, the theory-in-use that Lee (2010) mentions is reflected in most of those textbooks, which treat systems as technical artifacts, configurations of hardware, and software that are used by users. For example, Dennis, Wixom, and Roth (2009, pp. 4-5) say that "The analysis phase answers the questions of who will use the system, what the system will do, and where and when it will be used", and that "The design phase decides how the system will operate, in terms of hardware, software, and network infrastructure; the user interface, forms and reports; and the specific programs, databases, and files that will be needed". Similar views of "the system" appear in the first chapters of Valacich, George, and Hoffer (2012), Kendall and Kendall (2011), and Mathiassen, MunkMadsen, Neilsen, and Stage (2000).

The widely accepted definition-in-practice of systems as technical artifacts leads to restricted views and sometimes confusion regarding major IS research topics such as how IT-reliant systems operate in organizations, how to implement IT-reliant systems in organizations, what determines their success, and how IT contributes to productivity and profitability. For example, according to Brynjolfsson (2003), "IT is only the tip of a much larger iceberg of complementary investments that are the real drivers of productivity growth. In fact, our research found that for every dollar of IT hardware capital that a company owns, there are up to $\$ 9$ of IT-related intangible assets, such as human capital - the capitalized value of training - and organizational capital - the capitalized value of investments in new business-process and other organizational practices". A subsequent book by Brynjolfsson and Saunders (2010) cites related research that focuses on complementarities between IT, business processes, organizational capital, and other investments. In contrast to results such as these, one of the most widely cited models in IS is the Delone-McLean IS success model (Delone \& McLean, 1992, 2002), which treats the system as a technical artifact - a thing that is used.

Seeing systems as technical artifacts also affects views of important topics such as system life cycles and user participation. For example, in a useful update of the concept of user participation, Markus and Mao (2004) treat the system as a technical artifact, but observe that:

In many "IS" projects today, it is difficult to differentiate the system from the other aspects of an IT-based business intervention, such as process redesign, physical layouts of the workplace, changes in job design and compensation, or development of IT infrastructure. Indeed, many authors have argued that IT investments deliver the greatest business value when they are combined with "complementary changes" (p. 526).

Alter (2009) reviews aspects of Markus and Mao (2004) and explains advantages of replacing "user participation" with an approach that focuses more directly on work systems that produce business results.

There is wide agreement that IT-related projects have disappointing success rates and often generate less value than promised. Inadequate requirements are often cited as part of the problem; for example, see Wetherbe (1991), Byrd, Cossick, \& Zmud (1992), Markus and Mao (2004), Appan and Browne (2012). The examples in the paragraphs above illustrate ways in which system-as-technicalartifact and use-of-technology perspectives shift the focus away from essential, non-technical aspects of generating business results that managers care about. Addressing business and organizational 
issues more directly and more completely requires visualizing the system as though central aspects of Brynjolfsson's "complementary investments" and "intangible assets" are integral parts of the system, not just part of a context of use. Focusing more directly on generating business results that managers care about could lead to better requirements and more valuable IS research.

This paper presents work system theory (WST) in order to address these issues. WST replaces the prevailing system-as-technical-artifact perspective with a genuine system perspective for focusing on IT-reliant systems in organizations. That perspective treats human participants (frequently including customers, especially in service situations) as part of the systems that generate business results, not just as users of technology. Business processes are part of those systems, too, not just the context in which technology is used. WST also emphasizes the products/services that are produced and the value of those products/services because the purpose of systems in organizations is to produce products/services for the organisation's internal and/or external customers.

This paper's coverage of WST clarifies and extends ideas that were developed over two decades and have appeared in academic literature for almost as long (e.g., Alter, 1995, 1999a, 2000, 2001a, 2001b, 2002b, 2002c, 2006b, 2008a, 2010a). Aspects of those ideas have been used and cited in the literature, usually in reference to an evolving systems analysis and design method for business professionals called the work system method (WSM). The term work system also appears in the literature in contexts unrelated to WSM. For example, in the first edition of MIS Quarterly, Bostrom and Heinen (1977a, 1977b) speak extensively of work systems, but do not define the term precisely. Work system appears occasionally in the sociotechnical literature (e.g., Davis \& Taylor, 1979, p. xv; Mumford, 2000; Mumford \& Weir,1979, p. 3; Trist, 1981, p. 11). It has been used in other contexts by Sumner and Ryan (1994), Mitchell and Zmud (1999) Jasperson, Carter, and Zmud (2005), and many other authors, and also by consultants and researchers speaking of "high-performance work systems".

This paper provides three types of contributions. First, it presents a current, overarching view of WST, which emerged gradually during the trial-and-error process of developing and experimenting with various WSM versions. Clarifying the scope and content of WST at this point is important because WST was not differentiated from WSM during the first decade of WSM's evolution and because it is possible to apply WST without using WSM (as has occurred in recent research). Second, it summarizes progress related to extensions of WST, which includes overcoming important limitationsin-use of the work system framework, one of the two central frameworks in WST. Third, it identifies implications for future research and for the IS discipline as a whole that go far beyond the original effort to develop a systems analysis method for business professionals.

One can understand WST in relation to many diverse topics in the IS discipline, which include (among others) general system theory, organizational routines, systems analysis, system development, planned change, and emergent change. Instead of summarizing aspects of many diverse topics before introducing WST, this paper takes the more straightforward path of explaining WST first and subsequently relating it to other topics. The summary of WST in Section 2 defines work system and identifies implications of the definition. The definition leads to the two central frameworks in WST: the work system framework and work system life cycle model. Section 3 summarizes the work system method (WSM), which is based on WST. It includes a recent teaching version of WSM that illustrates the type of analysis and design in which WST can be used directly. Section 4 explains subsequent developments that have addressed three limitations-in-use of the work system framework. Section 5 presents comparisons with other theories. Section 6 provides an evaluation of progress to date. Section 7 closes the paper with new directions for research related to WST, and implications for the IS discipline. Two appendices provide additional perspectives. Appendix 1 summarizes the long-term research from which WST emerged, which includes differences between different versions of WSM. Appendix 2 uses a positioning map to show how WST is related to other topics in the IS discipline. 


\section{Work System Theory}

In relation to Gregor's (2006) categories of theories, work system theory (WST) is an integrated body of theory that includes a Type 1 analytical theory (the work system framework) and a Type 2 explanatory theory (the work system life cycle model), which in combination give the basis of a Type 5 design theory (WSM). WST provides a perspective for understanding systems in organizations, whether or not those systems use IT intensively. WST's domain of greatest relevance is IT-reliant work systems (defined below), which are arguably the core of the IS field (Alter, 2003a, 2003b). Implications and extensions of WST touch many other topics that are associated less directly with ITreliant work systems. To maintain focus, this paper assumes that WST's domain of relevance does not include important topics such as software per se, nuances of human-computer interaction, competitive uses of IT, business-IT alignment, IT strategies, project portfolios, technological change, the impact of IT on society, and the digital divide. Thus, while WST is relevant to many diverse aspects of systems in organizations, this paper does not claim that WST is some kind of theory of everything for the IS discipline.

WST is not presented here as a design theory even though it has been used as the basis for proposed improvements in many hundreds of work systems. WST emerged as a byproduct of research that started long before scholars recognized the current tenets of design science. The research that developed WSM and later articulated WST straddled two camps of DSR identified by Gregor and Hevner (2011, pp. 3-4): "The design-theory camp, exemplified by Walls, Widemeyer, \& El Sawy (1992), Markus, Majchrzak, and Gasser (2002), and Gregor and Jones (2007), promotes the importance of showing a design theory as the basis for the building of a design artifact. The pragmatic-design camp, exemplified by Nunamaker, Chen, \& Purdin (1990-91), March and Smith (1995), Hevner, March, Park, and Ram (2004), and livari (2007), is seen as agnostic to the need for design theory". The development of WSM was guided by the essence of WST, which was not articulated as a theory separate from WSM during the first decade of research.

This paper's stance in relation to longstanding debates about the legitimacy of different types of theory in IS and elsewhere (e.g., Gregor, 2006; Markus \& Robey, 1988; Sutton \& Staw, 1995; Weber, 2012; Weick, 1995) follows the view in the introduction of an edited book presenting various contributions to practice theory from noted sociologists, philosophers, and scholars of science:

Theory means, simply, general and abstract account. A theory of $X$ is a general and abstract account of $X$. [Theories include] typologies of social phenomena; models of social affairs; accounts of what social things (e.g., practices, institutions) are; conceptual frameworks developed expressly for depicting sociality; and descriptions of social life so long as they are couched in general, abstract terms. [That view leads to] using the expressions "practice theory", "practice thinking", and "the practice approach" interchangeably (Schatzki, 2001, pp. 12-13).

Much of WST's value is in supporting what might be called "work system thinking" related to systems in organizations and IS research. In contrast with a theory that describes relationships between several variables, WST was developed to serve the map-like role mentioned by Clarke \& Primo (2012): "Theories are like maps: the test of a map lies not in arbitrarily checking random points but in whether people find it useful to get somewhere". As Section 2.1 illustrates, WST supports work system thinking through a distinct perspective that looks at many important topics differently from the technology-as-system perspective that is common throughout IS practice and IS research.

\subsection{The Work System Concept}

The central idea in WST is that "work system" is a natural unit of analysis for thinking about systems in organizations. In organizational settings, work is the application of human, informational, physical, and other resources to produce products/services. A work system is a system in which human participants and/or machines perform work (processes and activities) using information, technology, and other resources to produce specific products/services for specific internal and/or external customers. Immediate implications of thinking of systems in organizations as work systems include: 
- By the system nature of work systems, the components and interactions in a work system should be in alignment, which implies that all components and interactions should be aligned with the work system's goals. Misalignments and performance gaps for components, interactions of components, and a work system as a whole are important reasons for modifying a work system.

- Based on the definition of work system, work systems exist to produce products/services for their customers. Accordingly, a work system's performance should be evaluated based partly on the efficiency and other aspects of internal processes and activities, and partially on customer evaluations of the products/services that are produced to provide value for internal and/or external customers.

- Based on the definition of work system, work systems may be sociotechnical systems in which people perform processes and activities. That possibility diverges significantly from the definition-in-practice in most systems analysis and design textbooks, whereby "the system" is a computerized artifact that is used by users. It is also diverges from similar assumptions in much IS research.

- In addition to sociotechnical work systems, the definition of work system also covers totally automated systems, including those revealed through decomposition of sociotechnical work systems during analysis and design processes. Applying WST as symmetrically as possible to both sociotechnical work systems and totally automated work systems may serve as a bridge between social scientists in the IS discipline who tend to focus on sociotechnical systems and technical specialists who tend to focus on internal operation and user interfaces of totally automated systems (e.g., Alter, 2010a).

- Based on accumulated real world experience and many hundreds of published and unpublished accounts of sociotechnical systems in organizations, work systems are assumed to evolve over time through a combination of planned change and emergent (unplanned) change. Those changes involve changes not only in hardware and software (the primary focus of IT-oriented life cycle models), but also in all other components of a work system.

Typical business organizations contain work systems that procure materials from suppliers, produce products, deliver products to customers, find customers, create financial reports, hire employees, coordinate work across departments, and perform many other functions. Almost all value chain systems (e.g., systems for inbound logistics, operations, sales and marketing, and customer service) and support systems (e.g., systems for procurement and human resources) are IT-reliant work systems that use IT in order to operate efficiently and effectively. Most are not IT systems, however, because they are not about IT. To illustrate the domain of WST, Table 1 lists representative examples of work systems that were analyzed in recent years by employed MBA students who produced management briefings about work systems in their own organizations. While entire enterprises or organizations can be viewed as work systems, the useful domain for work system analysis involves specific work systems within organizations, such as those listed in Table 1. 
Table 1. Examples of Work Systems Selected and Analyzed by Employed MBA Students

- Renewing insurance policies

- Receiving materials at a large warehouse

- Controlling marketing expenses

- Performing pre-employment background checks

- Performing financial planning for wealthy individuals

- Invoicing for construction work
- Planning and dispatching trucking services

- Scheduling and tracking health service appointments

- Operating an engineering call center

- Administering grant budgets

- Collection and reporting of sales data for a wholesaler - Approving real estate loans
- Finding and serving clients of a marketing consulting firm

- Determining government incentives for providing employee training

- Planning for outages in key real time information systems

- Acknowledging gifts at a high profile charitable organization

Work system is a general case for thinking about systems in or across organizations. There are many important special cases that should inherit most of the properties that are applicable to the general case. Examples include:

- Information systems, which are work systems whose processes and activities are totally devoted to processing information through activities that include capturing, transmitting, storing, retrieving, deleting, manipulating, and displaying information (Alter, 2008a).

- Supply chains, which are inter-organizational work systems whose goal is to provide supplies and other resources required for the operation of organizations that use whatever the supply chain produces.

- Projects, which are temporary work systems that are designed to produce a set of products/ services, after which they cease to exist.

- Self-service work systems, such as selecting and purchasing products/services using ecommerce web sites, which have customers as primary participants. In self-service, customers who perform processes and activities use resources provided for their use to obtain information, make purchases, or achieve other goals.

- Totally automated work systems, which are work systems in which all of the processes and activities are performed by computer programs, physical machines, and other devices. People who create and maintain those programs, machines, and other devices are not participants in those automated work systems. Rather, they are participants in other work systems that create or maintain automated work systems.

Many work systems use software that is part of commercial enterprise resource planning (ERP) and customer relationship management (CRM) packages. These software packages are best viewed as infrastructure shared by multiple work systems; the programs that are used in a specific work system can be viewed as part of the technology in that work system.

As a complete perspective on work systems, WST needs to cover both a static view of a work system during a period when it is relatively stable and a dynamic view of how a work system changes over time. The work system framework (Figure 1) is a pictorial representation of a work system in terms of nine elements included in a basic understanding of the work system's form, function, and environment during a period when it is relatively stable, even though incremental changes may occur during that period. The work system life cycle model (Figure 2) is a pictorial representation of the iterative process through which work systems evolve over time via a combination of planned change (formal projects) and emergent (unplanned) change that occurs through adaptations, bricolage (Ciborra, 1999, 2002), and workarounds. 


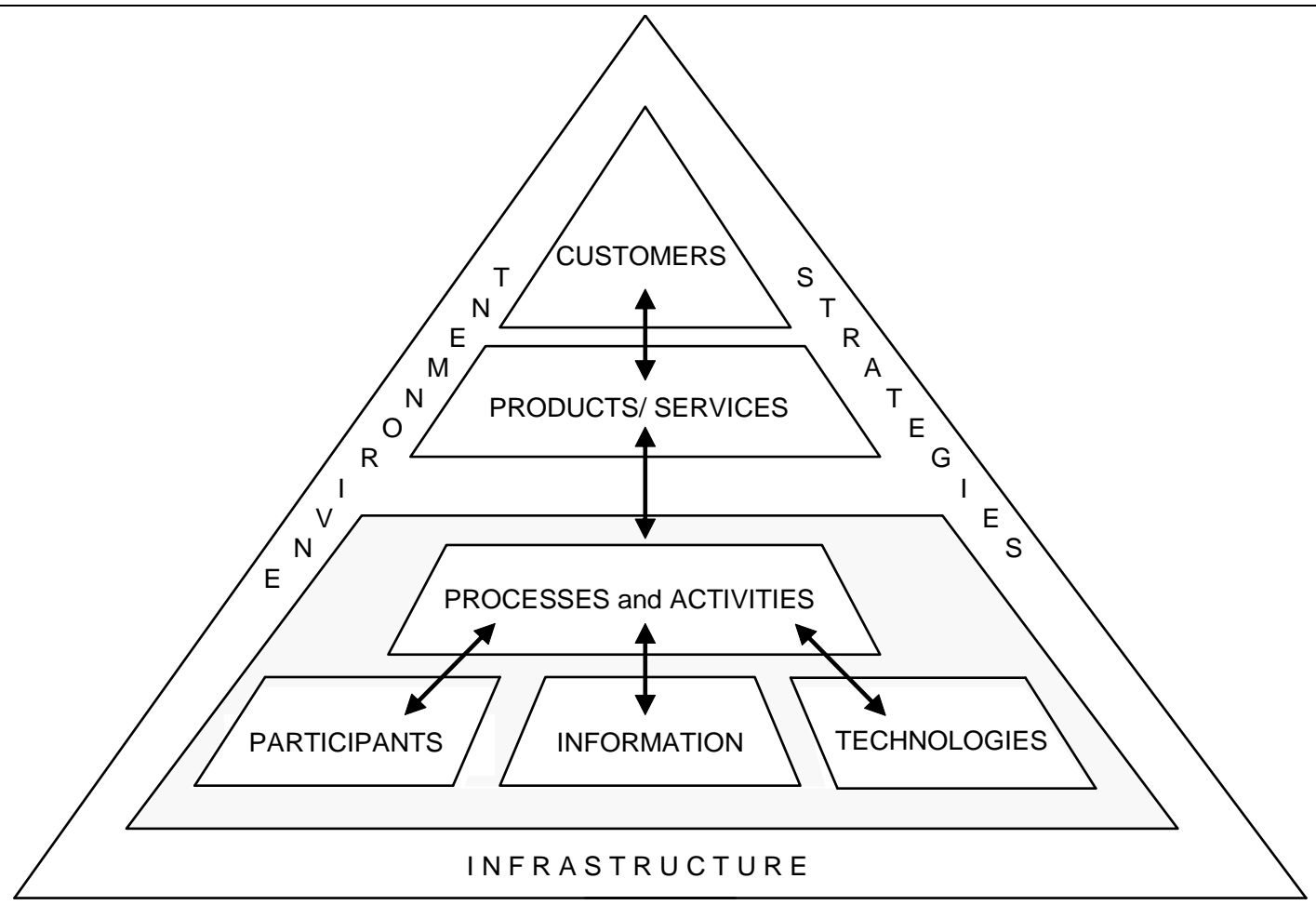

\section{Figure 1. The Work System Framework}



Unanticipated adaptations

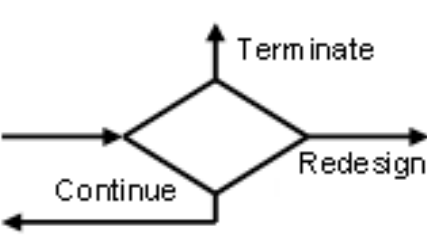

unanticipated opportunities

Ready for implementation

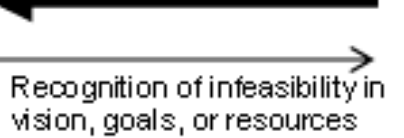

\section{DEVELOPMENT} vision, goals, or resources



Figure 2. The Work System Life Cycle Model (Alter, 2008a, 2008b) 


\subsection{Work System Framework}

The work system framework is a useful basis for describing and analyzing an IT-reliant work system in an organization because its nine elements are part of a basic understanding of a work system. The framework outlines a work system's form, function, and environment. It emphasizes business rather than IT concerns. It covers situations that might or might not have a tightly defined business process and might or might not be IT-intensive. Of the nine elements in the work system framework:

- Processes and activities, participants, information, and technologies are viewed as completely in the work system

- Customers and products/services may be partially inside and partially outside because customers often participate in the processes and activities within the work system and because products/services take shape in the work system, and

- Environment, infrastructure, and strategies are viewed as largely outside the work system even though they have direct effects in the work system.

Figure 1 shows that work systems exist to produce products/services for customers. One implication for analysis and design is that there is an inherent trade-off between internal management concerns about performing the work efficiently and maintaining the morale of the participants versus customer concerns about the total cost, quality, and other characteristics of the products/services that they receive.

The arrows inside the work system framework say that the specific elements of a work system should be in alignment. For example, the knowledge, skills, interests, and motivation of the participants should fit with the processes and activities in the work system. Conversely, the processes and activities should be appropriate for attributes of the participants. Changes in the processes and activities may require related changes in the participants ranging from additional training or new incentives all the way through changing participant roles, replacing some participants with others, or automating parts of the work, which thereby renders some roles unnecessary. Similar alignment issues apply for all pairs of elements that are linked by arrows.

Notice that there is no arrow linking participants and technology. The underlying assumption is that the main relationships and main needs for alignment are between the process and participants, process and information, and process and technologies. This assumption seems adequate for broadbrush work system thinking by most business professionals in most situations. The work system metamodel that is introduced later provides a more detailed representation designed to support more detailed analysis that is closer to the kind of analysis and design done by IT professionals. That metamodel includes an explicit link between participants and specific tools that they use to perform activities within a work system.

Table 2 summarizes reasons why the inclusion of each element in the work system framework is necessary for even a basic understanding of a work system. 
Table 2. Reasons for Including Each Element of the Work System Framework

\begin{tabular}{|c|c|}
\hline Element & Reason for inclusion in the work system framework \\
\hline $\begin{array}{l}\text { Processes and } \\
\text { activities }\end{array}$ & $\begin{array}{l}\text { Processes and activities occur in a work system to produce products/services for its } \\
\text { customers. A work system must contain at least one activity. Otherwise it does not } \\
\text { do anything. Use of the term "processes and activities" recognizes that the work } \\
\text { being performed may not be a set of clearly specified steps whose beginning, } \\
\text { sequential flow, and end are defined well enough to call it a process by some } \\
\text { definitions. Many important work systems perform organized activities that rely } \\
\text { heavily on human judgment and improvisation (e.g., Hall \& Johnson, 2009; Hill, } \\
\text { Yates, Jones, \& Kogan, 2006), are semi-structured, and are better described as a } \\
\text { set of related activities. In relation to systems analysis and design, processes and } \\
\text { activities in a work system are viewed from a performative perspective, focusing on } \\
\text { how the work actually is performed, rather than an ostensive perspective describing } \\
\text { an idealized notion of how the work should be performed (a distinction from Feldman } \\
\text { \& Pentland, 2003). }\end{array}$ \\
\hline Participants & $\begin{array}{l}\text { Participants are people who perform work within the work system, including both users } \\
\text { and non-users of IT. Failure to include participants in an analysis automatically would } \\
\text { omit important sources of variation in the results. Inclusion of the term participant } \\
\text { instead of the term user avoids ignoring important participants who do not use } \\
\text { computers and minimizes confusion due to referring to stakeholders as users, whether } \\
\text { or not they actually use the technology in a work system that is being analyzed. } \\
\text { Customers are often participants in work systems, especially in service systems. }\end{array}$ \\
\hline Inforr & $\begin{array}{l}\text { All work systems use or create information, which in the context of work system } \\
\text { analysis is expressed as informational entities that are used, created, captured, } \\
\text { transmitted, stored, retrieved, manipulated, updated, displayed, and/or deleted by } \\
\text { processes and activities. Typical informational entities include orders, invoices, } \\
\text { warranties, schedules, income statements, reservations, medical histories, resumes, } \\
\text { job descriptions, and job offers. Informational entities may contain other informational } \\
\text { entities. For example, an order may contain a line item and a document may contain } \\
\text { a chapter. The distinction between data and information is not important for } \\
\text { understanding a work system since the only data/ information that is mentioned is } \\
\text { information that is created, used or processed by the work system. Note also that } \\
\text { information within a work system includes information that is captured or represented } \\
\text { by computers and other information that is never computerized, such as the content } \\
\text { of conversations and verbal commitments and unrecorded information/ knowledge } \\
\text { that is used by work system participants as they perform processes and activities } \\
\text { within the work system. }\end{array}$ \\
\hline Technologies & $\begin{array}{l}\text { Almost all significant work systems rely on technology in order to operate. } \\
\text { Technologies include both tools that are used by work system participants and } \\
\text { automated agents; that is, hardware/software configurations that perform totally } \\
\text { automated activities. This distinction is crucial as work systems are decomposed into } \\
\text { successively smaller subsystems, some of which are totally automated. }\end{array}$ \\
\hline $\begin{array}{l}\text { Products/ } \\
\text { services }\end{array}$ & $\begin{array}{l}\text { Work systems exist in order to produce things for their customers. Ignoring what a } \\
\text { work system produces is tantamount to ignoring its effectiveness. Products/services } \\
\text { consist of information, physical things, and/or actions produced by a work system for } \\
\text { the benefit and use of its customers. The term "products/services" is used because } \\
\text { the controversial distinction between products and services in marketing and service } \\
\text { science (Chesbrough \& Spohrer, 2006) is not important for WST or WSM even } \\
\text { though product-like vs. service-like is the basis of a series of valuable design } \\
\text { dimensions for characterizing and designing the things that a work system produces } \\
\text { (Alter, 2010d, pp. 206-207). }\end{array}$ \\
\hline
\end{tabular}


Table 2. Reasons for Including Each Element of the Work System Framework (cont.)

\begin{tabular}{|c|c|}
\hline Element & usion in the work system framework \\
\hline Customers & $\begin{array}{l}\text { Customers are recipients of a work system's products/ services for purposes other } \\
\text { than performing work activities within the work system. Since work systems exist to } \\
\text { produce products/services for their customers, an analysis of a work system should } \\
\text { consider who the customers are, what they want, and how they use whatever the } \\
\text { work system produces. External customers are work system customers who are the } \\
\text { enterprise's customers, whereas internal customers are work system customers who } \\
\text { are employed by the enterprise, such as customers of a payroll work system. } \\
\text { Customers of a work system often are also participants in the work system (e.g., } \\
\text { patients in a medical exam, students in an educational setting, and clients in a } \\
\text { consulting engagement). }\end{array}$ \\
\hline Environment & $\begin{array}{l}\text { Environment includes the relevant organizational, cultural, competitive, technical, } \\
\text { regulatory, and demographic environment within which the work system operates, } \\
\text { and that affects the work system's effectiveness and efficiency. Organizational } \\
\text { aspects of the environment include stakeholders, policies and procedures, and } \\
\text { organizational history and politics, all of which are relevant to the operational } \\
\text { efficiency and effectiveness of many work systems. Factors in a work system's } \\
\text { environment may have direct or indirect impacts on its performance results, } \\
\text { aspiration levels, goals, and requirements for change. Analysis, design, evaluation, } \\
\text { and/or research efforts that ignore important factors in the environment may overlook } \\
\text { issues that degrade work system performance or even cause system failure. }\end{array}$ \\
\hline Infrastructure & $\begin{array}{l}\text { Infrastructure includes relevant human, information, and technical resources that are } \\
\text { used by the work system but are managed outside of it and are shared with other } \\
\text { work systems. From an organizational viewpoint such as that expressed in Star and } \\
\text { Bowker (2002) rather than a purely technical viewpoint, infrastructure includes } \\
\text { human infrastructure, informational infrastructure, and technical infrastructure, all of } \\
\text { which can be essential to a work system's operation and therefore should be } \\
\text { considered in any analysis of a work system. }\end{array}$ \\
\hline Strategies & $\begin{array}{l}\text { Strategies that are relevant to a work system include enterprise strategy, department } \\
\text { strategy, and work system strategy. In general, strategies at the three levels should } \\
\text { be in alignment, and work system strategies should support department and } \\
\text { enterprise strategies. Unfortunately, strategies at any of the three levels may not be } \\
\text { articulated or may be inconsistent with reality or with beliefs and understandings of } \\
\text { important stakeholders. }\end{array}$ \\
\hline
\end{tabular}

\subsection{Work System Life Cycle Model}

Figure 2 depicts the work system life cycle model (WSLC) that expresses a dynamic view of how work systems change over time through iterations involving planned change and emergent (unplanned) change (Alter 2006b, 2008a, 2008b, 2009, 2010d).

The WSLC represents planned change as projects that include initiation, development, and implementation phases. Development involves creation or acquisition of resources required for implementation of desired changes in the organization. Development may include any of the following: software development, software acquisition, software configuration, creation of new procedures, creation of documentation and training materials, and acquisition of any other resources needed for implementation of the new version of the work system. In contrast with the view of implementation in most software development methods, in the WSLC, implementation refers to implementation in the organization, not implementation of algorithms on computers. Markus and Mao (2004) uses the terms development and implementation in a similar way. 
The WSLC represents emergent change using inward-facing arrows that represent ongoing adaptations, bricolage, and workarounds that change aspects of the current work system without separate allocation of significant project resources. The inward-facing arrows for all four phases of the WSLC emphasize that emergence occurs through not only incremental changes in operational systems, but also changes that occur in different phases of formal projects. The inward-facing arrow for the operation and maintenance phase starts with short term adaptations and workarounds of cumbersome processes. It also includes longer-term changes in practices or goals that occur as adaptations and workarounds are incorporated into organizational routines (e.g., Feldman \& Pentland, 2003) without requiring formal projects. Emergence during the initiation phase may lead to goals that were not initially anticipated; emergence during the development phase may lead to new understandings and new combinations of functions and issues that were not anticipated in the initiation phase; emergence during the implementation phase may lead to modifications of initial intentions concerning important aspects of the "to-be" work system, which includes process and activity patterns, uses of technology and information, and expectations related to responsibilities and activities of work system participants.

The WSLC differs fundamentally from the "system development life cycle" (SDLC), which is basically a project model rather than a system life cycle. Some current versions of the SDLC contain iterations, but even those are iterations within a project. The system in the SDLC is a basically a technical artifact that is being created. In contrast, the system in the WSLC is a work system that evolves over time through multiple iterations. That evolution occurs through a combination of defined projects and incremental changes resulting from adaptations, making do with whatever is available, and creating workarounds to bypass obstacles. In contrast with control-oriented versions of the SDLC, the WSLC treats unplanned changes as part of a work system's natural evolution. Comparing the WSLC with alternative system development life cycle approaches is beyond this paper's scope. A currently outdated initial discussion of this topic appeared in Alter (2001b).

Since many terms related to work systems have been introduced, at this point is it worthwhile to provide a glossary of terms (Table 3) that incorporate the term work system. The glossary is also important because different people have used these terms in different ways, sometimes demonstrating a lack of clarity about the difference between the work system approach, WSM, and work system framework.

Table 3. Definition of Key Concepts in Work System Theory

\begin{tabular}{|c|l|}
\hline Concept & \multicolumn{1}{c|}{ Definition in relation to WST } \\
\hline Work & $\begin{array}{l}\text { In organizational settings, the use of human, informational, physical, and } \\
\text { other resources to produce products/services. }\end{array}$ \\
\hline Work system & $\begin{array}{l}\text { A system in which human participants and/or machines perform work } \\
\text { (processes and activities) using information, technology, and other } \\
\text { resources to produce products/services for internal and/or external } \\
\text { customers. Work systems are sociotechnical systems by default, although } \\
\text { the definition also encompasses totally automated work systems with no } \\
\text { human participants. }\end{array}$ \\
\hline $\begin{array}{c}\text { Special cases of work } \\
\text { systems }\end{array}$ & $\begin{array}{l}\text { Special cases of work systems include information systems, supply chains, } \\
\text { projects, self-service work systems, and totally automated work systems, } \\
\text { among others. For example, an information system is a work system in } \\
\text { which all of the processes and activities involve processing information. } \\
\text { Most concepts related to work systems in general are inherited by the } \\
\text { special cases. }\end{array}$ \\
\hline
\end{tabular}




\section{Table 3. Definition of Key Concepts in Work System Theory (cont.)}

\begin{tabular}{|c|c|}
\hline Concept & Definition in relation to WST \\
\hline $\begin{array}{l}\text { Work system theory } \\
\text { (WST) }\end{array}$ & $\begin{array}{l}\text { In relation to Gregor's (2006) categories of theories, work system theory } \\
\text { (WST) is an integrated body of theory that includes a Type } 1 \text { analytical } \\
\text { theory (the work system framework) and a Type } 2 \text { explanatory theory (the } \\
\text { work system life cycle model), which in combination give the basis of a Type } \\
5 \text { design theory (WSM). }\end{array}$ \\
\hline Work system approach & Synonym of work system theory (following Schatzki, 2001) \\
\hline Work system framework & $\begin{array}{l}\text { Representation of } 9 \text { elements of a basic understanding of a work system as } \\
\text { it exists during a time span when it maintains its identity and integrity even } \\
\text { though incremental changes may modify certain details of its form and/or } \\
\text { function. }\end{array}$ \\
\hline $\begin{array}{l}\text { Work system life cycle } \\
\text { model (WSLC) }\end{array}$ & $\begin{array}{l}\text { Representation of the iterative process by which work systems evolve over } \\
\text { time through a combination of planned change (projects) and emergent } \\
\text { (unplanned) change that occurs through bricolage, adaptations, and } \\
\text { workarounds. }\end{array}$ \\
\hline $\begin{array}{l}\text { Work system method } \\
\text { (WSM) }\end{array}$ & $\begin{array}{l}\text { Systems analysis and design method based on analyzing an "as-is" work } \\
\text { system and designing an improved version called the "to-be" work system. } \\
\text { Different versions of WSM have been used, with shortcomings of previous } \\
\text { versions leading to improvements in subsequent versions. }\end{array}$ \\
\hline Work system snapshot & $\begin{array}{l}\text { A basic tool used in WSM. A formatted, one-page summary of the work } \\
\text { system in terms of six elements of the work system framework: processes } \\
\text { and activities, participants, information, technologies, products/services } \\
\text { produced, and customers of the work system. Used for summarizing the } \\
\text { "as-is" work system and the recommended "to-be" work system. }\end{array}$ \\
\hline Work system principles & General principles that should apply to all work systems (summarized later). \\
\hline $\begin{array}{l}\text { Work system design } \\
\text { spaces }\end{array}$ & $\begin{array}{l}\text { A set of design spaces based on the work system framework that may help } \\
\text { business and/or IT professionals identify possibilities for improving a work } \\
\text { system (summarized later). }\end{array}$ \\
\hline Work system metamodel & $\begin{array}{l}\text { Conceptual model identifying entity types and relationships that can be } \\
\text { used to describe a work system in more detail than is represented by the } \\
\text { work system framework (summarized later). }\end{array}$ \\
\hline
\end{tabular}

\section{The Work System Method}

WSM is a flexible system analysis and design method that is based on WST. It treats the system of interest as a work system and builds on the two central frameworks in WST: the work system framework and WSLC. WSM was created for use by business professionals, and can be used jointly by business and IT professionals as part of the initial analysis for designing work system improvements that may or may not involve producing software. It can be used for high-level guidance in thinking about a work system or can organize a relatively detailed analysis through use of a work system analysis template. WSM was originally developed as a straightforward application of general problem solving that started from whatever work system problems, opportunities, or issues launched the analysis. The most notable aspect of WSM in relation to other analysis and design methods is that the "as-is" and "to-be" systems are work systems rather than configurations of hardware and software that are used by users. 
WSM was designed to be usable for different purposes and at different levels of detail because the specifics of a situation determine the nature of the understanding and analysis that is required. An executive can use WSM at a highly summarized level in the initiation phase of the WSLC to think about whether a system-related investment proposal is actually about improving a work system (rather than just acquiring software), and whether the comparison of the "as-is" and "to-be" work systems convincingly implies that business performance will improve. A manager may simply want to ask questions to make sure someone else has done a thoughtful analysis. Implementers, change agents, and work system participants can use various aspects of WSM to think about how the "as-is" work system operates, how well it operates, and how and why possible changes might generate better results for the organization and for specific stakeholders. IT professionals can use the ideas in WSM for understanding system-related situations from a business viewpoint and for communicating more effectively with business professionals who are the customers for their work.

\subsection{Evolution of WSM}

To maintain this paper's focus on WST, an explanation of the evolution of WSM through a number of versions with different levels of detail and slightly different purposes is deferred to Appendix 1.

To date, over 700 student papers using various versions of work system analysis templates have been collected from courses in the United States, China, Vietnam, and Australia. The vast majority of these papers were produced by employed MBA or Executive MBA students doing a preliminary analysis of a work system in an organization that they or a team member worked in. Results from analyzing these papers appear in Alter (2006a), Truex, Alter, and Long (2010), and Truex, Lakew, Alter, \& Sarkar (2011). The literature includes other reports related to applying work system concepts related to ERP systems (Petkov \& Petkova, 2008, 2010) and use of simplified work system analysis by freshman IS students (Recker \& Alter, 2012).

\subsection{Illustrative Example}

Table 4 (next page) illustrates the general logic of WSM by summarizing a business case template used by Executive MBA students in Vietnam in 2012. This template was used for a final group paper in a short course designed to combine an overview of work system analysis with an overview of project management. After considering IT-reliant work systems in their own organizations, each group selected a single IT-reliant work system with important problems or opportunities. The groups applied work system thinking by conceiving the situation in work system terms, summarizing the "as-is" work system, drilling down to understand the problems and opportunities in more detail, and proposing a "to-be" work system. The justification of the proposal had to consider the project of converting from the "as-is" work system to the "to-be" work system, thereby including project management issues covered in the course. Because the students were working full time, their analyses were necessarily much more cursory than a real world analysis should be. In particular, there was very little opportunity to gather data other than any data that already existed in the setting.

Appendix 1 presents a number of other variations on WSM. The main commonality between all of them is that the situation is conceived as a work system with performance problems or opportunities and that the "as-is" and "to-be" work systems are summarized using the format of a work system snapshot. In all cases, the scope of the work system is treated as a choice rather a given. The general rule of thumb is that the work system for the analysis is the smallest work system that exhibits the problems or opportunities that motivated the analysis. 
Table 4. Example of the Work System Method in the Form of a Business Case Template

\begin{tabular}{|c|c|}
\hline Main Heading & Topics included \\
\hline 1. Executive summary & $\begin{array}{l}\text { 1. Brief summary of the "as-is" work system, the problem, and the } \\
\text { proposed improvements. }\end{array}$ \\
\hline 2. Background & $\begin{array}{l}\text { 1. Brief background needed to understand the context of the } \\
\text { analysis. }\end{array}$ \\
\hline 3. System and problem & $\begin{array}{l}\text { 1. Name of work system } \\
\text { 2. Main problems or opportunities } \\
\text { 3. Significance of the work system } \\
\text { 4. Constraints that limit the possible recommendations } \\
\text { 5. Internal performance gaps (related to processes, participants, } \\
\text { information, technologies) } \\
\text { 6. External performance gaps (related to customers and } \\
\text { products/services) } \\
\text { 7. Discussion of performance gaps } \\
\text { 8. Work system snapshot of the "as-is" work system } \\
\text { 9. Customer value and customer concerns for primary customers } \\
\text { 10. Customer responsibilities for primary customers }\end{array}$ \\
\hline 4. Analysis and possibilities & $\begin{array}{l}\text { (Looking at the situation through various lenses, such as issues in } \\
\text { the process rationale, Pareto analysis, fish-bone diagrams, etc.) }\end{array}$ \\
\hline $\begin{array}{l}\text { 5. Recommendation and } \\
\text { justification }\end{array}$ & $\begin{array}{l}\text { 1. Summary of recommendation } \\
\text { 2. Work system snapshot of the "to-be" work system } \\
\text { 3. Likely impact of recommended changes } \\
\text { 4. Brief summary of the cost/benefit rationale }\end{array}$ \\
\hline 6. Project plan & $\begin{array}{l}\text { 1. Project ownership and governance } \\
\text { 2. Criteria and method for evaluating success } \\
\text { 3. Summary of the project (main steps, dates, deliverables, } \\
\text { resources) } \\
\text { 4. Major risks and pitfalls }\end{array}$ \\
\hline
\end{tabular}

\subsection{Work System Snapshot}

Table 5 is an example of the "work system snapshot" mentioned in Table 4. It is a formatted onepage summary of a work system in terms of the six central elements of the work system framework: customers, products/services, processes and activities, participants, information, and technologies (Alter, 2006b, 2008a, 2008b, 2010d). The example in Table 5 combines aspects of several work system snapshots related to hiring systems. The requirement of not exceeding one page helps focus attention on the scope of the system and prevents getting overwhelmed at the outset in details that subsequent analysis will reveal.

The other three elements of the work system framework (environment, infrastructure, and strategies) are not included in the work system snapshot for the sake of simplicity when focusing on the appropriate scope for the work system in relation to the problems and opportunities at hand. These three elements are considered as the analysis goes into more depth. The distinction between technical infrastructure and technology within the work system is unimportant for a first-cut summary but may prove important later as the analysis distinguishes between technologies that are directly associated with the specific work system and other technologies that are shared by multiple work systems.

Despite their textual nature, work system snapshots require rigorous thinking guided by the following consistency rules: 
- Each of the processes and activities listed in the work system snapshot must be stated as a complete sentence that briefly specifies which participants perform the work and what they do.

- Each participant group must be involved in at least one step in the processes and activities. Customers are viewed as participants if they participate in at least one of the steps.

- Each informational entity and technological entity listed under information and technologies must be created or used in at least one step in the processes and activities.

- Each product/service in the work system snapshot must be the output of at least one step in the processes and activities.

- Each product/service must be received and used by at least one customer group.

- Each customer group must receive and use at least one product/service.

\section{Table 5. Work System Snapshot of a Recommended "To-Be" Work System}

\begin{tabular}{|c|c|}
\hline Customers & Products/services \\
\hline $\begin{array}{l}\text { Hiring manager } \\
\text { Larger organization (which will employ the new } \\
\text { hire) } \\
\text { HR manager (who will analyze the nature of } \\
\text { applications) }\end{array}$ & $\begin{array}{l}\text { Applications (which may be used for subsequent } \\
\text { analysis) } \\
\text { Job offers } \\
\text { Rejection letters } \\
\text { Hiring of an applicant }\end{array}$ \\
\hline
\end{tabular}

Hiring manager submits request for new hire within existing budget.

Staffing coordinator defines the parameters of the new position.

Staffing coordinator publicizes the position.

Applicants submit job applications.

Staffing coordinator selects shortlisted applicants.

Hiring manager identifies applicants to interview.

Staffing coordinator sets up interviews.

Hiring manager and other interviewers perform interviews.

Hiring manager and other interviewers provide feedback from the interviews.

Hiring manager makes hiring decisions.

Staffing assistant sends offer letters or rejections.

Successful applicant accepts or rejects job offer or negotiates further.

\begin{tabular}{|l|l|l|}
\hline \multicolumn{1}{|c|}{ Participants } & \multicolumn{1}{c|}{ Information } & \multicolumn{1}{c|}{ Technologies } \\
\hline Hiring managers & Job requisition & New HR portal that is being built \\
Staffing coordinator & Job description & Word processor \\
Applicants & Advertisements & Telephones \\
Staffing assistant & Eob applications & \\
Other employees who perform & Cover letters & \\
interviews & Applicant resumes & \\
& Short list of applicants & \\
& Information and impressions & \\
& from the interviews & \\
& Job offers & \\
& Rejection letters & \\
\hline
\end{tabular}




\section{Extensions Beyond Central WST Concepts}

Sections 2 and 3 present the concept of a work system, the work system framework (a static view of a work system), and the work system life cycle model (a dynamic view of how a work system changes over time). They also summarize WSM, which applies those ideas. This section presents three extensions of WST that were developed to address limitations observed in uses of WSM: work system principles, work system design spaces, and a new work system metamodel.

These extensions are mentioned to illustrate how additional ideas and frameworks extended WST in order to support analysis of work systems in ways not anticipated in the initial research. Such extensions are not surprising, given that many other system-related methods and tools have evolved over time and that follow-on generations of many products and innovations have gone beyond the intentions and scope of the original versions. This paper treats these extensions as useful developments that are outside of the core of WST.

\subsection{Work System Principles}

The idea of defining work system principles and incorporating them in WSM was motivated by difficulties encountered by MBA and Executive MBA teams in accomplishing more than describing a work system and identifying several readily apparent weaknesses. The elements of the work system framework provided a good outline for summarizing a work system using a work system snapshot (Table 5), but many teams had difficulty searching for improvements other than relatively obvious changes such as recording data that wasn't being recorded or sharing data that wasn't being shared. They seemed to need guidelines for thinking about the various types of improvements that might be considered. Introducing a general set of work system principles seemed a plausible way to make sure that the teams would think about each element and would have a basis for comparing the current status and possible modifications to a set of ideals.

The 2002 version of WSM (Alter, 2002a) uses seven principles for evaluating any work system independent of problems and opportunities that launched the analysis. A broader set of work system principles developed iteratively between 2002 and 2004 included nine sociotechnical principles from Cherns (1976) that were adapted to make them more understandable to typical business professionals, plus additional principles based on comments and feedback from academic colleagues and Executive MBA students. The resulting set of 24 work system principles seemed to strike a reasonable compromise between completeness and complexity (Alter, 2004b). Those principles were introduced to six cohorts of Executive MBA students at the University of San Francisco between 2005 and 2009. As reported by Alter and Wright (2010), individual students in these cohorts rated each principle for "correctness", the extent to which most work systems in their organizations should conform to the principle, and "conformance", the extent to which most work systems actually did conform to the principle. A table of principles was included in work system analysis templates used during 2005 to 2007. The principles table was removed from later versions because it seemed not to yield much additional value beyond the insight from other parts of the template. In a broader sense, the effort of producing the 24 principles raises questions about how work system principles might really be useful, about the point of diminishing returns for additions to any set of such principles, and about how to validate the current 24 principles or any other set of work system principles (e.g., see Markus et al., 2002).

\subsection{Work System Design Spaces}

Like most systems analysis and design methods, initial versions of WSM proved stronger on providing analysis and documentation techniques and weaker on guiding the identification of potential improvements to an existing work system. The attempt to develop work system principles was an initial attempt to provide more guidance in searching for potential improvements. A subsequent step was to specify a set of "design spaces" identifying generic types of changes or directions for change, thereby helping analysts consider improvement paths that they might not otherwise imagine or recognize as relevant. 
A work system design space is an organized set of common work system changes, common directions for change, and/or factors whose problematic nature might impel change in relation to work system elements, subsystems of a work system, or a work system as a whole. To date, six such design spaces have been described. Most have been used informally as a reference by MBA and Executive MBA students analyzing systems in organizations. No data was collected about whether those design spaces influenced their thinking. The design spaces described to date include the following:

1) Work system principles (above) have implications for design because they can be used as a checklist or point of comparison by thinking about the extent to which the "as-is" or "to-be" work system conforms to each principle. In each case, gaps between "as is," "to be," and "should be" provide potential directions for improvement.

2) Generic types of changes occur frequently for each of the six elements in a work system snapshot (Alter, 2006b, 2010b, 2010e). Some are in the spirit (Markus \& Silver, 2008) of engineering, such as adding, combining, or eliminating steps in a process, or upgrading hardware and software. Others are more in the spirit of service, such as changing the nature of customer relationships or the customer experience. Scanning a checklist of these generic changes organized in the format of a work system snapshot can help in identifying possible directions for improvement, e.g., Should we add or eliminate steps? Should we change business rules? Should we change the nature of the customer relationship? and so on.

3) Design characteristics for each element in a work system snapshot (plus "work system as a whole") represent big picture choices that should be considered before determining a work system's details (Alter, 2006b, 2010b, 2010e). Each characteristic can be treated as a design dimension, such as from simple to complex, from unstructured to totally structured, and from manual to automated. The related questions include: How structured should this process be? How complex should it be? What is the right amount of variety in the work? and so on. Typical systems analysis and design texts for IS students say little or nothing about these design characteristics.

4) Common risks and obstacles are often associated with each element of the work system framework and with the work system as a whole (Alter, 2006b, p. 66). Analysts and designers can use this design space to identify common risks and obstacles that may apply to the work system but that may not be named yet or fully visualized in the analysis. Next they can decide whether each common risk or obstacle presents a significant issue for the work system and can try to devise ways to minimize the related problems.

5) Alternative locations of information and knowledge are relevant because information and knowledge can reside within any of the work system elements. Where knowledge should reside, and in what form, can be viewed as a design choice. For example, knowledge about aspects of a particular work system might be tacit knowledge in the heads of work system participants, might be built into the overall logic of processes and activities and into business rules for specific activities, might be codified in expert systems, or might be built into hardware or software technologies to support skilled workers or guide less skilled workers (Alter, 2010b, 2010e).

6) Direct and indirect interactions with other work systems. Those interactions may be essential for a work system's successful operation (e.g., interactions with suppliers or customers) or may cause the work system's performance to degrade or even fail catastrophically (e.g., interactions involving sharing of essential resources such as participants or computers). The basis of this design space is a set of concepts and taxonomies for understanding, analyzing, and designing interactions between ITreliant work systems (Alter, 2010c, 2012d). 


\subsection{Work System Metamodel}

Both classroom discussions and written assignments produced by MBA and Executive MBA students occasionally reveal confusions and ambiguities related to the work system framework. Examples discussed in Alter (2010a) call for a framework that would provide greater clarity about concepts and more specific guidance about relationships that are often important. Such a framework should support deeper, more detailed analysis without requiring terminology (e.g., objects and classes) that is impenetrable to most business professionals.

Alter (2010a) presents a work system metamodel that in essence is a more detailed specification of the work system framework. The metamodel takes the form of a conceptual model (Wand \& Weber, 2002) that contains 31 entity types and numerous relationships (Alter, 2010a, p. 10). Each element of the work system framework is represented, although most are re-interpreted in a more detailed form. For example, information becomes informational entity, technology becomes technological entity and is divided into tools and automated agents, activities are performed by one of three types of actor, and so on. Whereas the work system framework does not include the term user, the metamodel includes "uses" as a relationship between the entity type "participant" and the entity type "tool" (one of two distinct guises of technology). Attributes of entity types, such as goals, characteristics, metrics, principles, and other concepts are not shown in the metamodel diagram, just as attributes of classes might not be shown in a UML class diagram if the purpose was to identify classes and relationships between classes. Analysts using the metamodel would apply those attributes while defining the problem or opportunity, evaluating the "as-is" work system, and justifying proposed improvements that would appear in the "to-be" work system.

The development and inclusion of the work system metamodel is consistent with the tenet of design science research (e.g., Hevner et al., 2004) that the shortcomings of designed artifacts should be identified and remedied if possible. In this case, the work system framework is useful for high-level analysis and design but is less effective in supporting detailed analysis and design. That is where the metamodel takes over. For example, the metamodel says that each activity is performed by up to three types of actor roles: non-customer participant, customer participant, and automated agent. The participant roles are performed by specific participants whose attributes such as skills, knowledge, interests, and motives strongly affect performance outcomes. Every activity uses resources that may include participants, informational entities, technological entities, and other resources. Every activity produces products/services that may be resources for other activities and/or may be received by the work system's customers for use outside of the work system. All of those relationships are clear from the metamodel and can be the basis of straightforward analysis and design tools even though they are not clear from the work system framework.

The metamodel has been applied in subsequent research. It was extended as a metamodel for service system design (Alter, 2011a, 2012b) in which service systems are work systems that produce services and may be part of larger value constellations (Normann and Ramirez, 1993). It was also applied in research about developing guidelines for converting work system snapshots into UML use case diagrams, thereby supporting transitions from business-oriented descriptions to technical documentation for programming. Neither the basic premises of WST nor the work system framework are specific enough to guide that type of conversion process. With its more detailed representation of WST ideas, the metamodel provides the basis for a new tabular summary that lists each activity in a work system along with the resources that it uses, the products/services that it creates, and relevant triggers, pre-conditions, and post-conditions. (Alter \& Bolloju, 2012; Alter, 2012c).

The foregoing background, including WST's core and its extensions, provide a basis for positioning WST in relation to other aspects of the IS discipline that focus on systems in organizations. That comparison is presented in Appendix 2. 


\section{Comparison of WST with Other Theories and Perspectives}

The essential point in WST is that systems can be viewed as work systems, a term that is defined in a particular way and that provides a lens for describing both how systems operate (the work system framework) and how they change over time (WSLC). A number of other theories and perspectives provide their own unique lenses related to systems in organizations. Of those, this paper compares WST briefly with seven very different perspectives, all of which are relevant to one or another aspect of understanding systems in organizations, which is the basic purpose of WST. Those perspectives include general systems theory, sociotechnical systems theory, actor-network theory, theory of organizational routines, soft systems methodology, activity theory, and the Unified Modeling Language (UML). WST might have been compared with many other theories listed in the AISWorld wiki on theories used in IS research (Schneberger \& Wade, 2012). The seven that were chosen seemed to be the ones most directly related to the general goals of describing, understanding, analyzing, and designing systems in organizations. Either directly or indirectly, most of them provided part of the context in which WSM and WST developed.

Comparing WST with various system development approaches is beyond this paper's scope because WST is not a system development method just as WSM is not a system development method, but rather, an adaptable method for analyzing and designing work systems. WST and various aspects of WSM can be used in conjunction with many system development approaches including waterfall development, agile development, prototyping, installation and configuration of commercial software packages, use of software as a service, end user computing, and so on. In each case, WST ideas for thinking about work systems and work system improvement processes are potentially valuable for clarifying desired impacts on work systems and anticipating difficulties that may occur.

\subsection{General Systems Theory}

An initial point of comparison is general systems theory (GST), which includes many widely applicable concepts and observations about systems; for example, Boulding (1964), Forrester (1971), Weinberg (1975), Miller (1978), Churchman (1979), Ackoff (1981), Beer (1981), Checkland (1999). Skyttner (2005, pp. 56-57) notes that a system is not something presented to an observer; rather, it is something to be recognized by an observer. Skyttner (2005) cites definitions of system such as, "anything that is not chaos" (Boulding, 1964), "a structure that has organized components" (Churchman, 1979), and "a set of variables sufficiently isolated to stay constant long enough for us to discuss it" (Ashby, 1956). GST "integrates a broad range of special system theories by naming and identifying patterns and processes common to all of them. By use of an overarching terminology, it tries to explain their origin, stability and evolution. While special systems theory explains the particular system, GST explains the systemness itself, regardless of class or level" (Skyttner, 1996, p. 16).

WST is basically a special case within GST that focuses on systems in organizations. GST provides basic concepts for thinking of situations as systems, such as boundary, environment, input, output, transformation, and state. WST reframes those concepts in relation to systems in organizations, and therefore is much less general than GST. In relation to WST's domain of application, a shortcoming of GST and various short lists of GST concepts (e.g., open system vs. closed system, subsystem, form, function, boundary, environment, interface) is that the short lists do not provide enough guidance to be helpful in many specific types of situations. For example, asking a doctor to describe medical services in terms of form, function, boundary, environment and several other very general terms might yield some results, but probably is not specific enough to be helpful in most situations. An inquiry about whether WSM might embrace GST more fully (Alter, 2007) was inconclusive. It recognized overlaps in basic ideas but noted that Skyttner (2005, pp. 99-103) lists 39 "widely known laws, principles, theorems, and hypotheses" associated with GST. It might be value to explore whether and how each of those topics could add to an understanding of work systems.

\subsection{Sociotechnical System Theory}

The sociotechnical systems approach focuses on joint optimization of social and technical subsystems within organizations (Cherns, 1976; Davis \& Taylor, 1979; Lamb \& Kling, 2003; 
Majchrzak \& Gasser, 2000; Majchrzak \& Borys, 2001; Pasmore, 1985; Thomas, Gupta, \& Bostrom, 2008; Trist, 1981). Two articles with sociotechnical themes (Bostrom \& Heinen, 1977a, 1977b) appeared in the first volume of MIS Quarterly, but attempts to develop systems analysis and design methods with a sociotechnical focus have not been prominent in the IS discipline or in IS practice. Examples of such methods include Mumford's ETHICS methodology (Mumford \& Weir, 1979; Hirschheim \& Klein, 1994), client-led design (Stowell \& West, 1995), and Multiview (Avison, WoodHarper, Vidgen, \& Wood, 1998).

Although work systems are viewed as sociotechnical systems by default, WST does not follow the tradition of separating social systems versus technical systems (Mumford \& Weir, 1979; Hirschheim \& Klein, 1994). Instead, it views the social and the technical as part of a single system. As mentioned earlier, sociotechnical principles of Cherns (1976) provided an important starting point for nine of the 24 work system principles. Despite the default assumption that systems are sociotechnical, WST and WSM extend beyond the purely sociotechnical realm by covering totally automated systems that perform work without human intervention once they are launched into action by an external stimulus. That step beyond the purely sociotechnical is important for understanding and analyzing increasingly automated systems that are important in today's business and society.

\subsection{Actor-Network Theory}

Actor-network theory (ANT) provides a way to view a situation as a network of human and nonhuman actors, each with its own agency. ANT addresses the issue of how such networks are established and maintained through "moments of translation" involving problematization, interessement, enrolment and mobilization, as was introduced in Callon's (1986) widely cited article about the scallops and the fishermen of St. Brieuc Bay. It might be possible to articulate valuable synergies between those ideas and WSLC, especially since those ideas are relevant in each WSLC phase. It is possible that ANT concepts could enrich WSLC by highlighting continual sensemaking and negotiation that WSLC deemphasizes. That topic is especially interesting for the selection, configuration, and installation of software packages for use within work systems.

There are longstanding debates in the IS discipline and elsewhere about the extent to which human and nonhuman actors should be treated as symmetrical components of actor networks. Rose, Jones, and Truex (2005, pp.134-135) note that, with Giddens' view of agency as "the capability to make a difference", an agent can be viewed as "something that produces an effect or change", such as a chemical agent, or when applied to people, "a person who does something or instigates some activity". However, they also note that "Giddens' (1984) treatment of structuration theory views agency as synonymous with human action".

By defining work systems as systems in which human participants and/or machines perform work, WST tries to treat human and non-human actors as symmetrically as possible without ignoring relevant topics such as uniquely human capabilities and weaknesses. The system nature of work systems implies that agency resides in every human and non-human element of the work system framework because every element may impel or constrain action. Since the different types of elements of the work system are fundamentally different, it is possible to associate different types of agency with different elements of the work system framework; for example:

- Agency of customers (who demand particular levels of cost and quality)

- Agency of products/services (which, in effect, demand specific forms and levels of production capabilities)

- Agency of processes (whose sequence and business rules force or guide participants to act in certain ways)

- Agency of participants (who perform work based on their personal capabilities, needs, and emotions) 
- Agency of information (which may impel or constrain action based on its content and expression in the world)

- Agency of technology (in the guise of tools that add to users' capabilities or as automated agents that perform work autonomously), and

- Agency of various aspects of the environment (which affect whether the work system can operate efficiently and effectively).

Identifying these types of agency implies that the frequently mentioned social/human versus material/technical duality (e.g., Cecez-Kecmanovic, Galliers, Henfridsson, Newell, \& Vidgen, 2010) might be augmented by focusing on different types of agency when trying to describe and understand work systems in practice (Alter, 2011b).

\subsection{Theory of Organizational Routines}

Feldman and Pentland (2003) present "a new theory of organizational routines" that makes it easier to see how stability and change in organizational routines are related. They state that "An organizational routine is a repetitive, recognizable pattern of interdependent actions, involving multiple actors" (p. 96). The theory identifies two aspects of organizational routines. The ostensive aspect is:

the ideal or schematic form of a routine. The performative aspect consists of specific actions, by specific people, in specific places and times. It is the routine in practice... The ostensive aspect of the routine cannot encompass specific performances because it is impossible to specify any routine in sufficient detail that it could actually be carried out (p. 101).

For example, subsequent research related to invoice processing, a presumably stable type of organizational routine, found "hundreds of unique patterns that changed significantly during a fivemonth period without any apparent external intervention" and that "increased automation can increase variation under some circumstances" (Pentland, Haerem, \& Hillison, 2011, p. 1369).

An organizational routine might be viewed as a very common special case of a work system in which work consists of repetitive, situated, interdependent actions of multiple actors based on shared understandings. Work system is a broader notion since it also encompasses projects, supply chains, uses of ecommerce websites, and other situations in which activities may be distributed in space and time, may or may not be repetitive, and may or may not be based on shared understandings of multiple interdependent actors. By including both sociotechnical and totally automated work systems, WST also extends the literal notion of organizational routine (repetitive, recognizable pattern of interdependent actions, involving multiple actors) into situations in which important actors are nonhuman.

The distinction between ostensive and performative is quite significant when thinking about work systems. A performative aspect of processes and activities is essential for WSM because the goal is to understand how well an existing work system operates and to create an improved version whose performance will be better. Any divergence between the performative aspect and the ostensive aspect is important for any realistic analysis and design effort. The distinction between ostensive and performative is the basis of two central figures in Appendix 2, which discusses the position of WST in relation to the rest of the IS discipline.

\subsection{Soft Systems Methodology}

SSM is an important perspective that was developed over three decades by Checkland (1999). SSM

was developed in response to the perceived failure of traditional systems engineering (SE), particularly with regards to management problems... The primary contribution of SSM is in the analysis of complex situations where there are divergent views about the definition of the problem. SSM was developed as a means for understanding and dealing with the diversity of views and interests (Mingers \& White, 2010, p, 1151). 
Although SSM is much more concerned than WST and WSM with the philosophical underpinnings of systems thinking, SSM's six key aspects of a "human activity system", customers, actors, transformations, world view, owners, and environment, often abbreviated CATWOE, can be compared with the nine elements of the work system framework. Notice however, that WST covers not only human activity systems, but also totally automated work systems.

LIke WSM, SSM evolved over time. Checkland (1999, p. A11) notes that an appendix in Holwell's 1997 thesis "contains four different representations of SSM between 1972 and 1990 and correctly suggests that these show how the methodology has become less structured and broader as it has developed". SSM originally used a seven step process, but was described more recently as four steps directed at finding out about a problem, formulating relevant activity models, debating the situation and conflicting interests, and taking action. In other words, detailed comparison of WSM with SSM would have to select among multiple versions of each.

A description of SSM that was available in the early 1990s seemed to be too abstract and too philosophical to be used effectively by most (American) MBA and EMBA students. Accordingly, the original versions of WSM were designed to be very flexible but also much more prescriptive than SSM and much more direct about suggesting topics and issues that are often relevant to understanding IT-reliant work systems. Since WST is a byproduct of the development of WSM, that early assumption may have affected the focus of WST.

\subsection{Activity Theory}

Activity theory is a theory for analysis that can be traced back to Vygotsky's work on cultural-historical psychology. It was introduced to an international audience in the late 1970s and 1980s through works by Leontiev and others. It can be viewed as "a framework for thinking about human activity as it is expressed in the use of technology", It is based on the following tenets: an emphasis on human intentionality, the asymmetry of people and things, the importance of human development, and the idea of culture and society as shaping human activity (Kaptelinin \& Nardi, 2006, pp. 9-10).

A paper that compared an activity-driven approach with WSM and SSM said, "Activity Theory (AT) is a socio-cultural theory which has been applied mostly in the fields of learning and education, and work development and since the 1980's in the field of software development and ISD". With an activity-driven approach,

the starting point and the focus of ISD activities should be work itself, not just plain IS or software requirements. Within a systemic work activity, several people work upon a shared object in an organized way to produce a common outcome. The elements of a work activity are: actors, object, work process, outcome, means of work, means of coordination and communication, collective actor and the mode of operation (Luukkonen, Korpela, \& Mykkänen, 2010, p. 8).

In contrast to those elements, a triangular activity system model (Kaptelinen \& Nardi, 2006, p. 100) adapted from Engeström (1990) contains the following constructs: rules, community, division of labor, subject, object, outcome, and tools. In that model, tools appear at the top of the triangle just as customers are at the top of the work system framework. It is difficult to generalize about how a work system analyst might proceed differently if using WST/ WSM versus using activity theory since different authors represent activity theory differently. By applying both activity theory and the work system framework to the replacement of project managers, Vartiainen et al. (2011) provides an example that could be used in such a comparison.

\subsection{Universal Modeling Language (UML)}

The Unified Modeling Language (UML) can be viewed as a theory related to systems in organizations because it provides a well-articulated perspective and vocabulary for identifying technical system components and specifying how they behave. Its modeling language views situations as consisting of objects that behave and interact according to properties and methods that they receive from the 
abstract classes to which they belong. Systems specified using UML are totally technical systems that are described starting with use cases that can be linked to work system snapshots or other work systems summaries based on WST (Alter \& Bolloju, 2012). While UML does not seem to fit with most of the other theories mentioned here, it is included in this section because moving a step closer to UML-like descriptions of work systems might facilitate creation of software specifications based on discussions about sociotechnical work systems between business and IT professionals. The work system metamodel was designed as a step in that direction.

It might be possible to go much further. The spirit of steps toward UML might be similar to the spirit of steps toward modeling work systems in relation to service-oriented architecture (SOA). To a computer scientist, SOA is a computer system architecture based on a metaphor of clients and servers that interact through unambiguous messages in pre-specified formats (e.g., Brown, Delbaere, Eeles, Johnston, \& Weaver, 2005) just as objects interact through unambiguous messages in UML. The promise of technically mediated service-orientation of a broader type is expressed in an SOA maturity model (Welke, Hirschheim, \& Schwarz, 2011) whose SOA maturity dimension goes from technical concerns to business capabilities. That dimension starts with infrastructure efficiency and reuse and moves toward enterprise flexibility and agility and enterprise transformation. At that end of the spectrum SOA is sometimes rebranded as SOE - "service-oriented enterprises" (e.g., Demirkan \& Goul, 2006) and is described in statements such as "in the service-oriented enterprise, every activity has an explicitly identified customer to whom that service has value; and each of those customers has an outcome that they want to achieve" (Graves, 2009, p. 23).

The label SOE is tantalizing because it sounds like something that most managers and organizations would want even though a computer science view of service-orientation is ill-suited for most interactions between human providers and human customers. The work system framework already expresses a micro version of an SOE approach because work systems exist to produce products/services for customers, the customers evaluate the products/services, and the customers are at the top. Adopting a definition of service that makes sense in both a computer realm and a human realm might be an additional step in that direction (e.g., Alter, 2010d). From the other side, it would be interesting to see an example of a "genuinely service oriented enterprise" (Alter, 2012a, p. 1) that reconciled practical SOA methods and service excellence from a human customer's perspective. Any practical path to SOE surely must go through work systems because organizations consist of work systems. That path also must go through a series of specification technologies (e.g., UDDI, WSDL, and SOAP) that represent the same spirit of rigorous, technically inspired modeling as appears in UML applications. The work system metamodel and other aspects of the attempt to move from work system summaries to UML specifications may contribute in some way to achieving a more satisfying level of service-orientation at an enterprise level.

\section{Evaluation of Work System Theory}

The following evaluation of WST considers four criteria that are pertinent to almost any theory in IS: relevance, novelty, clarity, and usefulness.

\subsection{Relevance: Does WST Address Important Issues?}

As explained in the introduction, WST addresses central issues in the IS discipline related to how people think about systems. WST provides an alternative to the frequently taken-for-granted techno-centric assumption that systems should be viewed as configurations of hardware and software that are used by users. The alternative view in WST is potentially useful to practitioners who need to focus on business operations and business results rather than on uses of technology. That view might lead to better collaboration between business and IT professionals by providing a better basis for mutual understanding. It also addresses fundamental IS research issues such as how IT-reliant systems operate in organizations, how to implement IT-reliant systems in organizations, what determines their success, and how IT contributes to productivity and profitability. Finally, it might help in improving traditionally problematic introductory IS courses by providing a more understandable link between technology topics and business concerns since technology is an essential component of most work systems. 


\subsection{Novelty: Does WST Say Anything That is New or Different?}

Section 5 and other parts of this paper summarize a number of ways in which WST overlaps with and differs from other theories and methods related to systems in organizations. No other system-related theory or method that the author is aware of shares most of the following characteristics of WST:

- WST starts with a clear definition of work system.

- WST covers both sociotechnical and totally automated systems.

- WST includes both a static view of a work system during a period when it is relatively stable (the work system framework) and a dynamic view of how a work system changes over time (the WSLC model).

- The static view emphasizes the performative aspect of processes and activities (how work is actually performed) while recognizing the importance of the ostensive aspect (how work should be performed in accordance with formal design specifications).

- The dynamic view includes both planned change and unplanned (emergent) change.

- Information systems and projects can be treated as special cases of work systems that inherit properties of work systems in general.

- WST is the basis of a flexible systems analysis method (WSM), different versions of which potentially allow business professionals and/or IT professionals to use work system ideas for collaboration and for their own unique purposes.

- Applying WST suggests many extensions that use or reinterpret the same core ideas. As will be explained in Appendix 2, various extensions of WST move toward ostensive or performative aspects of static or dynamic views of systems, and hence toward many diverse concepts and methods in the IS discipline.

\subsection{Clarity: Is WST Articulated Clearly?}

WST is articulated carefully, starting with definitions of work and work system. Those definitions lead to the work system framework (Figure 1 and Table 3) and work system life cycle model (Figure 2), which are also part of WST.

This paper's distinction between WST and WSM clarifies the theoretical basis of WSM and addresses confusion between different versions of WSM that have been used in the past (e.g., Table 4 and versions mentioned in Appendix 1). For example, either explicitly or unknowingly, some authors have cited specific versions of WSM going back to 2002, while other authors have referred to WSM without specifying any particular version.

The distinction between WST and WSM also clarifies the fact that it is possible to use and extend WST without using WSM. The various versions of WSM are applications of WST concepts. Experience with various versions of WSM demonstrated the need for extensions such as work system principles, work system design spaces, and the work system metamodel. Additional extensions shown in Appendix 2 build on those ideas. WST can serve as a base for those extensions because its concepts and internal relationships are clear. 


\subsection{Usefulness: Is WST Useful for Teaching, Practice, and Research?}

To date, most of WST's usage has occurred in educational settings or in IS research.

\subsubsection{Usage in Teaching}

As Appendix 1 explains, WSM's initial development was an outgrowth of 1992, 1996, 1999, and 2002 editions an introductory IS textbook that ultimately was used by several hundred thousand students and their instructors. The first edition hinted at a work system approach in a number of ways including an initial form of the work system framework. The 1996 and 1999 editions described "work-centered analysis", which was replaced by "principle-based analysis" in the 2002 edition. The term work system method first appeared in a journal article in 2002 and as the title of a book in 2006. (Alter, 2002c, 2006b). An indication of the visibility of the textbooks is that a Google Scholar search on "work-centered analysis", a term that appeared only in the second and third editions, found research papers by authors associated with universities in Australia, Brazil, Canada, Czechoslovakia, Netherlands, Nigeria, Norway, United Arab Emirates, United Kingdom, and the United States.

The iterative development of different versions of WSM started after publication of the first edition of the textbook. Until 2008, the most intensive usage of various classroom versions of WSM was by students at the University of San Francisco. For example, Alter (2006a) reported pitfalls observed in 202 group papers by students between 1997 and 2003. Full-time and part-time MBA students in China produced 73 papers of similar quality during two 5-week courses in 2004. In addition to continued use at USF, intensive use included 300 management briefings produced over several years by MBA students at another US university and 19 similar analyses produced in short Executive MBA courses in Vietnam.

According to numerous anecdotal accounts of less intensive usage, the work system framework and other aspects of WSM have been used in North America, Europe, Asia, and Australia as a component of university courses for undergraduate business majors, undergraduate IS majors, generalist MBA and Executive MBA students, and MBAs majoring in IS. The courses have included introduction to IS, systems in organizations, technology-enabled innovation, systems analysis and design, business process improvement, IS development, and ERP systems. In some cases the usage involved one or several lectures to provide context for the course or for other topics. Some courses asked students to apply the work system framework to create work system snapshots as a basic exercise in work system thinking. The work system framework, work system principles, or sets of questions related to work system elements also have been used to establish the rationale for programming projects by computer science students. Journal articles that discuss uses of WSM or aspects of WST in teaching include: Kizior (2001), Ramiller (2002), Alter (2006a), Petkov and Petkova (2008, 2010), Adams (2009), Truex et al. (2010, 2011), Petkov, Petkova, Sewchurran, Andrew, and \& Misra (2012), and Recker and Alter (2012).

\subsubsection{Usage in Research}

Beyond its use in teaching, a number of researchers other than Alter have applied or cited the work system framework and other aspects of the work system approach in a broad range of contexts. To date, at least eight Ph.D. theses have used work system ideas in significant ways (Beekhuysen, 2009; Goldstein, 2009; Granlien, 2010; Kankaanpää, 2011; Lawrence, 2011; Litchfield, 2011; Petrie, 2004; Re, 2010;), as have a number of masters and bachelors theses. Many published citations to the concept of work system, the work system framework, WSLC, and WSM revealed contributions to a researcher's thinking. The following examples date from 2006 to 2012: Benbasat and Zmud (2006), Cuellar, McLean, and Johnson (2006), Curtin, Kauffman, and Riggins (2006), Davamanirajan, Kauffman, Kriebel, and Mukhopadhyay (2006), Gray (2006), Møller (2006), BenMoussa (2007), Goodhue (2007), Kurpjuweit and Winter (2007), Sewchurran and Petkov (2007), Davison, Ou, Li, Martinsons, and Bjorksten (2008), Kosaka (2008), Lyytinen and Newman (2008), Petkov and Petkova (2008), Petersson (2008), Singh and Woo (2008), Beekhuyzen (2009), Gericke and Winter (2009), Gregory and Descubes (2011), Kosaka (2009), Lafaye (2009), Madsen and Vigden (2009), Misra, Petkov, and Petkova (2009), Mettler (2009), Ou and Banerjee (2009), Pinhanez (2009), Ralph and Wand (2009), BenMoussa (2010), Cuellar (2010), Granlien (2010), Kampath and Röglinger (2010), 
Luukkonen et al. (2010), Oinas-Kukkonen (2010), Petkov and Petkova (2010), Wastell (2010), Winter (2010), Ahmad, Lyyitenen, and Newman (2011), Aier and Fischer (2011), Akter, Ray, and D'Ambra (2011), Baskerville (2011), Beverungen, Wittchen, and Becker (2011), Grgecic (2011), Hoermann, Schermann, and Krcmar (2011), Islam, Akter, Kashem, and Rahman (2011), Scheepers, Davis, Sonenberg, and Howard (2011), Sobyanina \& Mockutè (2011), Valkonen (2011), Vartiainen et al. (2011), Efeoglu et al. (2012), Elmaallam \& Kriouile (2012), Ferrario et al. (2012), Goldschmidt, Joseph, and Debowski (2012), Hosack, Hall, Paradice, and Courtney (2012), Lemey \& Poels (2012a, 2012b), Peng (2012), Panko (2012), Petkov et al. (2012), Roelens, Lemey, and Poels (2012), Sinisammal, Belt, Härkönen, Möttönen, and Väyrynen (2012). While an increasing number of citations have appeared, the extent to which WST and its applications and extensions will prove useful in IS research is not yet fully evident because of the lengthy time lags in diffusion of new ideas, use of those ideas in research, and eventual publication.

\subsubsection{Suggestive Evidence for Potential Application in Practice}

The work system framework appeared in a practitioner journal in an article called "Navigating the collaboration triangle" (Alter, 2002b). While many employed MBA and Executive MBA students have used aspects of WSM (and hence WST) in their jobs (e.g., a testimonial in Truex et al., 2010), currently there are no case studies or action research studies of its use in industry.

The best published evidence for the practical value of WST and related frameworks is from Truex et al. $(2010,2011)$, articles that summarize results from 75 and later 300 management briefings produced by employed MBA students based on a work system analysis template. These briefings contained the kind of analysis that would be discussed in the initiation phase of the WSLC while decisions were being made about which projects to pursue and how to proceed. The briefings were evaluated by one or two highly qualified evaluators (depending on the semester) based on perceived quality. The evaluators did not have independent information about the situations that were being analyzed. Instead, the evaluation of each management briefing was based on the evaluators' opinion regarding whether it made sense based on personal business experience and knowledge of the academic literature. Most of the individuals who produced the briefings had substantial business experience (an average of six years) and therefore were meaningful representatives of business professionals to whom WSM is directed. The evaluations found that most students produced understandable and at least reasonably well argued reports. The general quality of the results suggests that a work system approach can help business professionals think about IT-reliant systems analytically.

The overall conclusion based on experience to date is that most employed MBA and Executive MBA students are able to use recent classroom versions of WSM to come to a reasonably organized understanding of real world systems that are not pre-defined for them in case studies written by someone else. Different versions of WSM have different advantages and disadvantages in use, mostly related to tradeoffs between covering the full range of work system topics versus overwhelming the user by requiring more detailed analysis than is situationally appropriate. The author is not aware of any comparable research involving large number of employed business professionals using organized methods for analyzing systems in organizations.

\subsection{Difficulties Evaluating Usage of Broadly Applicable Theories and Methods}

A final comment about evaluation of WST concerns questions related to the ambiguity of the statement "person $X$ used theory $Y$ ". Ignoring issues about different versions of methods, that statement is unclear for almost any theory or method that can be used in many different ways and at different levels of depth. Consider, for example, the MBA students whose management briefings were discussed in Truex et al. (2010, 2011). They knew about the definition of work system and work system framework but did not know about the WSLC, work system principles, or the new metamodel, all of which were beyond the scope of their brief courses. They used work system ideas, but they might have produced better and more complete management briefings if they knew about other aspects of WST and its extensions. 
Previous research has discussed this type of issue both in general (e.g., Truex, Baskerville, \& Travis, 2000) and in relation to specific methods and tools. For example, research about the usage and limitations of UML and BPMN have found that many capabilities of each language are not used in most specific applications (Dobing \& Parsons, 2006, 2008; Recker, 2010; Siau, Erickson, \& Lee, 2005; zur Muehlen \& Recker, 2008). Consider an IS project that employs use cases and activity diagrams but does not use other UML diagrams. That project employs valuable, widely used tools, but may totally ignore the purported benefits of UML's object-orientation. Under those circumstances there is a question about whether the essence of UML is actually being used. Similar questions might be asked about whether an attempt to produce a rich picture is tantamount to using SSM, or whether drawing a picture with boundaries, inputs, outputs, some type of transformation, and possibly some type of controller qualifies as using GST in a meaningful way.

\section{Next Steps, Implications for the IS Discipline, and Conclusion}

Given the broad applicability of the work system concept, it is not surprising that the effort of developing WSM led in a number of directions that were beyond the originally envisioned scope of the project. Based on progress to date, a great deal of additional research is called for. Section 7.1 identifies directions for follow-on research that could evaluate WST and WSM more thoroughly and could lead to valuable extensions. Section 7.2 identifies broader implications for the IS discipline.

\subsection{Next Steps in Research}

Research directed toward further development and testing of WST, WSM and their extensions could be of substantial value to the IS discipline. The following are areas in which that research is underway or could occur in the future:

- Test various versions of WSM more thoroughly to determine their benefits and weaknesses, especially in real world situations. Such research might combine action research with design science research methods (e.g., Sein, Henfridsson, Purao, Rossi, \& Lindgren, 2011), thereby obtaining rich observations from one situation or just a few, the opposite of the approach used thus far in research related to WST and WSM.

- Determine the potential benefits of combining aspects of WST or WSM with aspects of agile development, the Rational Unified Process, or any other software development method. This would involve using aspects of WST or WSM to augment existing methods by establishing greater visibility of performance issues and business goals that might not be explored fully within existing methods that are directed toward creating or improving software systems. Also, this could involve developing guidelines for converting from work system snapshots and related tools to diagrams used in structured and object oriented systems analysis and design. Possible steps in that direction were reported in Alter, Bolloju, and Vogel (2009), Tan, Alter, and Siau (2011), and Alter and Bolloju (2012). Based on the most recent effort, it appears that the work system metamodel might play an important role in such guidelines because it is more precise than the work system framework.

- Further clarify conceptual distinctions related to the work system framework, such as participants vs. users, documented processes vs. organizational routines, espoused vs. enacted business processes, technical capabilities vs. technology-in-practice, technology as tool vs. technology as automated agent, products vs. services produced by a work system, customers as recipients vs. customers as payers vs. other stakeholders, different types of agency within a work system, alignment vs. congruence of systems and system components, and different types of interactions between work systems (basis of "system interaction theory" mentioned in Alter (2010c, 2012d).

- Further clarify important overlaps and interactions between the work system life cycle model and topics such as emergent change vs. planned change, diffusion of 
innovation, windows of opportunity (Tyre \& Orlikowski, 1994), punctuated equilibrium in systems (Lyytinen \& Newman, 2008), project risk (Sherer \& Alter, 2004), bricolage (Ciborra, 1999; 2002), moments of translation in ANT (Callon, 1986), and workarounds (basis of a proposed "theory of workarounds") .

- Develop methods for using WST within ERP and CRM implementations. Such methods would be based on recognition that the business value of ERP and CRM may be amplified or attenuated by the way the software is configured for specific work systems. This type of application might use some of the concepts of secondary design (Germonprez, Hovorka, \& Gal, 2011).

- Develop more effective ways to integrate WST into teaching and to demonstrate its pedagogical benefits. Petkov and Petkova $(2008,2010)$, Truex et al. $(2010,2011)$ and Recker and Alter (2012) report steps in this direction.

- Extend the comparison of WST and WSM with other theories and methods to try to develop hybrids that are better than existing theories and methods. For example, a detailed look at accounts of real world applications of SSM, ANT, organizational routines, practice theory, and activity theory could identify synergies that lead to better theories and methods.

- Integrate WSM with methods and tools that are typically viewed as external to the IS discipline, such as total quality management (TQM) and Six Sigma. For example, methods associated with Six Sigma such as root cause analysis, Pareto analysis, and the "5 whys" are certainly applicable when thinking about IT-reliant work systems. Such methods should be used wherever they might provide insight and where the required data is available or can be collected.

- Integrate WST and aspects of WSM within analysis and design for specific types of systems, such as supply chains or ecommerce systems. One such effort is an attempt to focus WST on service systems, the core subject matter of "service science" (Chesbrough \& Spohrer, 2006; Spohrer, Maglio, Bailey, \& Gruhl 2007). Steps in that direction include Alter (2008b, 2010d, 2012b).

- Formulate a Type 4 theory for explanation and prediction (Gregor, 2006) related to insights from WST for system modeling techniques in general. Related propositions would say that modeling techniques that encompass all or most of the work system framework will provide more comprehensive, and hence better analysis than techniques that focus on only one or several work system elements.

\subsection{Broader Implications For The IS Discipline}

Leading researchers have published many articles about the unsatisfying state of IS theory, of the body of knowledge in IS, and of the impact of IS research (e.g., Watson, 2001; Weber, 2003; Hirschheim \& Klein, 2003; livari, Hirschheim, \& Klein, 2004; Lyytinen \& King, 2004; Srinivasan, March, \& Saunders, 2005; Grover, Lyytinen, Srinivasan, \& Tan, 2008). Attention to the theoretical and practical strengths and limitations of WST and WSM could help researchers think about what they really want from IS theory and could also help them see directions for improving or extending IS theories that might or might not be directly related to WST.

One of this paper's contributions to knowledge is its explanation of WST as the basis of an integrated and evolving body of concepts, frameworks, and theory that extends beyond the term work system or the relatively familiar work system framework. This paper closes by identifying four directions for the future that could affect the IS discipline in a broader way. The ideas in each of these directions are based on WST, WSM, and related concepts, but go far beyond the original intention in developing WSM. 


\subsubsection{Think Differently about Systems and Their Impact on Business Results}

To increase its focus on the relationship between IT and business results, the IS discipline may need to place greater emphasis on how IT-reliant work systems operate and what they produce. That idea was proposed in Alter (2003b) as a response to the narrower scope of the nomological network described in Benbasat and Zmud (2003). That broader scope would be consistent with comments in this paper's introduction regarding the importance of "complementary assets" in attaining value from IT, and the fact that a work system approach treats more of those assets as part of "the system" or as essential elements in understanding the system. Greater emphasis on work systems is appropriate because the relationship between work system performance and business results is much more direct than the relationship between IT and business results. Srinivasan et al. (2005, p. 994) took a step in that direction by saying "organizations are themselves designed artifacts within which IT artifacts are implemented and used by people. Researchers must recognize the interdependencies among organizational design, IT artifact design, and the capabilities and limitations of the people for whom these artifacts are intended". Alter (2003a) goes further by arguing that IT-reliant work systems should be viewed as the core subject matter of the IS discipline. Wastell (2010) supports aspects of that view.

\subsubsection{Think Differently about User Participation and Implementation in Organizations}

The default assumption in much of the IS discipline is that systems are technical artifacts that users use, rather than sociotechnical systems in which people participate. In contrast, WST's default assumption is that human participants are essential elements of sociotechnical work systems, not just users of hardware and software. That is why the work system framework (Figure 1) contains the term participants rather than users.

If systems are viewed as work systems with participants, then the work system life cycle model or something like it is an appropriate model for describing how systems change over time, and certainly is more appropriate than a software-centric SDLC or agile programming model. Adopting a work system-centric change model would affect the way the IS discipline talks about "user participation" and "user involvement". For example, a critical look at Markus and Mao's (2004) review of the user participation literature argued that "project collaboration" and the work system life cycle model might be a better focal point for thinking about all those issues (Alter, 2009). A project collaboration approach would be less likely to misconstrue IS projects and IT projects. IS projects managed as work system projects might encounter less resistance and fewer surprises than IS projects managed as the creation and installation of IT artifacts. Contrary to the form of various SDLC models in the IS literature, the WSLC assumes that both planned and emergent (unplanned) change occur frequently, and that deviations from an existing plan or specification are natural occurrences in many situations rather than problems that must be avoided. A related area for research is an elaboration of the view of emergence and incremental change in the work system life cycle model. A current step in that direction is a proposed theory of workarounds (Alter, 2012e) that may help in explaining operational mechanisms within all four inward facing arrows in the WSLC.

\subsubsection{Think Differently about Systems Analysis and Design}

Thinking of systems as work systems with human participants rather than as technical artifacts leads to different assumptions about the nature and expectations for systems analysis and design. Systems with human participants often do not operate consistent with designer's understandings and intentions. The value of producing precise specifications of systems and software is often undermined by variability related to the capabilities and intentions of human participants. Recognizing that variability implies an explicit expectation that human participants may not follow whatever specifications or requirements may have been agreed upon, may work with different degrees of accuracy and commitment at different times, and may find a variety of justifiable and/or opportunistic ways to work around whatever rigorous specifications are built into software and processes that are supposed to use the software.

From that viewpoint, analysis should focus on how processes and/or organizational routines actually are performed, not just how they are supposed to be performed. Similarly, design should be viewed as guidelines for action rather than as strict determinants of action. The indeterminacy of systems with human participants implies that the design of most work systems cannot specify exactly what will 
happen inside of each non-automated step even though it can control activities to some extent by specifying triggering conditions, business rules, completion conditions, and post-conditions for activities within structured processes.

That same indeterminacy calls for systems analysis and design approaches that pay attention to articulation work, coordination, improvisation, and emergence. Those topics are downplayed or ignored in typical process models that focus mostly on work flows, triggering conditions, resource requirements, business rules, and post-conditions of specific activities. Extensions in that direction could incorporate ideas from bodies of research often viewed as unrelated to systems analysis and design, such as research involving gray spaces and emergent phenomena (e.g., Schmidt \& Bannon, 1992; Star \& Strauss, 1999; Suchman, 1987). While recognizing the importance of producing testable software, developing semi-rigorous systems analysis and design methods may be just as fruitful as developing modeling formalisms for creating increasingly precise specifications and requirements.

\subsubsection{Develop a Body of Knowledge for the IS Discipline}

Hirschheim and Klein (2003) call for a body of knowledge (BoK) for the IS discipline based on a broad synthesis that goes beyond "categorization schemes that make up the subject areas of IS (cf. Barki, Rivard, \& Talbot, 1988; Bacon \& Fitzgerald, 2001) ... but have not led to a discussion on how IS knowledge as a whole should be structured" (p. 244). "Defining a theoretically appealing, yet practically relevant, action-oriented body of knowledge could provide a type of 'Rosetta Stone' for IS as an applied discipline" (p. 263). Work system concepts based on WST and its extensions could provide a possible step in that direction.

A possible way to organize a BoK of IS in organizational contexts is based on the earlier observation that information systems in general and projects in general are actually special cases of work systems in general. A direct implication is that most properties of work systems in general are inherited by information systems in general. In other words, specifying the properties of work systems in general, including the relevant vocabulary, principles, and empirical findings, should be a good starting point for specifying the vocabulary, principles, and empirical findings that apply to information systems, projects, and special cases of information systems and projects. In contrast to BoK proposals by livari et al. (2004) and Hassan and Mathiassen (2009), it is possible that a BoK for the part of IS field that focuses on IS in organizations might be organized using a 3-dimensional conceptclassification matrix. The three dimensions include different types of knowledge, elements of the work system framework, and special cases of work systems (Alter, 2012e). A great deal of detailed work would be required to test the feasibility of this approach because a fully developed version of just the work system layer of the concept-classification matrix would include hundreds of concepts, principles, and theories that are used to communicate and codify knowledge about work systems. Experience in using experts to develop a BoK for supporting the process of organization design in manufacturing organizations (Markus et al., 2002, pp. 186-188) might provide useful background for such a project, although today it might be pursued using crowdsourcing or some other means.

Whether or not development of the concept-classification matrix seems feasible in practice, the thought experiment of imagining such a matrix may explain some of the difficulty of achieving the frequently stated goal of identifying core theories that are unique to the IS discipline (e.g., Weber, 2003). It is possible that most of the body of knowledge relevant to information systems and most of the valuable theories are either about work systems in general or about special cases of information systems, and that almost nothing of genuine interest can be said about information systems in general that is not also true of work systems in general (Alter, 2005, 2008a, 2012e).

\subsection{Conclusion}

This paper provides contributions in three areas. First, it presents an up-to-date view of WST.Second, it summarizes progress related to extensions of WST, including overcoming important limitations-inuse of the work system framework, one of the two central frameworks in WST. Third, it shows that WST has implications for future research and for the IS discipline as a whole that go far beyond the original effort to develop a systems analysis method for business professionals. Appendix 2 extends 
those ideas further. Each of the next steps in research listed above could generate results of substantial practical and theoretical value, ideally achieving a combination (not a tradeoff) of rigor and relevance because they are based on coherent ideas that are relevant to many important issues in practice. The concluding ideas about rethinking the IS discipline's view of systems, user participation, systems analysis, and a possible body of knowledge for the core of the IS discipline are also about major topics that that can be pursued by using WST, WSM, and their extensions.

\section{Acknowledgements}

I want to thank the senior editor, Shirley Gregor, and the excellent referees for their interest, encouragement, judgment, and fortitude during the process of producing this very long article. They provided a large number of useful criticisms and suggestions that helped in shaping and revising several iterations of the article. I especially appreciate Shirley Gregor's suggestions and encouragement throughout the entire process, which started at the end of the 2010 JAIS Theory Development Workshop. I also want to thank many hundreds of MBA and Executive MBA students whose analyses of systems in their own organizations helped me develop the ideas presented here. 


\section{References}

Ackoff, R. (1981). Creating the corporate future. New York: John Wiley \& Sons.

Adams, J. (2009). Establishing a model to identify information systems in Nontraditional organizations. Information Systems Education Journal, 7(88), 1-9.

Ahmad, A., Lyytinen, K., \& Newman, M. (2011). The evolution of process models in IS Research: From a punctuated social process model to a socio-technical process model. Proceedings of the European Conference on Information Systems.

Aier, S., \& Fischer, C. (2011). Criteria of progress for information systems design theories. Information Systems and E-Business Management, 9, 133-172

Akter, S., Ray, P., \& D'Ambra, J. (2011). Viewing systems as services: The role of service quality. Thirty Second International Conference on Information Systems, Shanghai.

Alter, S. (1992). Information systems: A management perspective $\left(1^{\text {st }}\right.$ Ed.). Reading, MA: AddisonWesley.

Alter, S. (1995). How should business professionals analyze information systems for themselves In E. Falkenberg, W. Hess, \& E. Olive (Eds.), Information system concepts: Toward a consolidation of views (pp. 284-299). Proceedings of the IFIP WG 8.1 Working Conference on Basic Information System Concepts, Marburg, Germany.

Alter, S. (1996). Information systems: A management perspective $\left(2^{\text {nd }}\right.$ Ed.). Menlo Park, CA: Benjamin/Cummings.

Alter, S. (1999a). A general, yet useful theory of information systems. Communications of the Association for Information Systems, (1)13, 1-70.

Alter, S. (1999b). Information systems: A management perspective ( $3^{\text {rd }}$ Ed.). Reading, MA: AddisonWesley.

Alter, S. (2000). Same words, different meanings: Are basic IS/IT concepts our self-imposed Tower of Babel? Communications of the Association for Information Systems, 3(10), 1-87.

Alter, S. (2001a). Are the fundamental concepts of information systems mostly about work systems? Communications of the Association for Information Systems, 5(11), 1-82.

Alter, (2001b). Which life cycle - work system, information system, or software? Communications of the Association for Information Systems, 7(17), 1-53.

Alter, S. (2002a). Information systems: The foundation of e-business $\left(4^{\text {th }}\right.$ Ed.). Upper Saddle River, $\mathrm{NJ}$ : Prentice-Hall.

Alter, S. (2002b). Navigating the collaboration triangle. CIO Insight, 21-27. Retrieved from http://www.cioinsight.com/c/a/Past-News/Whiteboard-the-Collaboration-Triangle/

Alter, S., (2002c). The work system method for understanding information systems and information system research. Communications of the Association for Information Systems, 9(6), 90-104.

Alter, S. (2003a). 18 reasons why IT-reliant work systems should replace the IT artifact as the core subject matter of the IS field. Communications of the Association for Information Systems, 12(23), 365-394.

Alter, S. (2003b). Sidestepping the IT artifact, scrapping the IS silo, and laying claim to "systems in organizations". Communications of the Association for Information Systems, 12(30), 494-526.

Alter, S. (2004a). Desperately seeking systems thinking in the IS discipline. Proceedings of ICIS-25, the International Conference on Information Systems, Washington, DC, 757-769.

Alter, S. (2004b). Making work system principles visible and usable in systems analysis and design. Proceedings of AMCIS 2004, the Americas Conference on Information Systems, New York, NY, 1604-1611.

Alter, S. (2005). Architecture of sysperanto: A model-based ontology of the IS field. Communications of the Association for Information Systems, 15(1), 1-40.

Alter, S. (2006a). Pitfalls in analyzing systems in organizations. Journal of Information System Education, 17(3), 295-302.

Alter, S. (2006b). The work system method: Connecting people, processes, and IT for business results. Larkspur, CA: Work System Press.

Alter, S. (2007). Could the work system method embrace systems concepts more fully? Information Resource Management Journal, 20(2), 33-43.

Alter, S. (2008a). Defining information systems as work systems: Implications for the IS field. European Journal of Information Systems, 17(5), 448-469. 
Alter, S. (2008b). Service system fundamentals: Work system, value chain, and life cycle. IBM Systems Journal, 47(1), 71-85.

Alter, S. (2009). Project collaboration, not just user participation. Proceedings of the Fifteenth Americas Conference on Information Systems, San Francisco, CA.

Alter, S. (2010a). Bridging the chasm between sociotechnical and technical views of systems in organizations. Proceedings of ICIS 2010, the 31st International Conference on Information Systems.

Alter, S. (2010b). Design spaces for sociotechnical systems. Proceedings of ECIS 2010, the 18th European Conference on Information Systems.

Alter, S. (2010c). Including work system co-existence, alignment, and coordination in systems analysis and design. Proceedings of the Sixteenth Americas Conference on Information Systems, Lima, Peru.

Alter, S. (2010d). Viewing systems as services: A fresh approach in the IS field. Communications of the Association for Information Systems, 26(11), 195-224.

Alter, S. (2010e). Work systems as the core of the design space for organisational design and engineering. International Journal of Organisational Design and Engineering, 1(1), 5-28.

Alter, S. (2011a). Metamodel for service design and service innovation: Integrating service activities, service systems, and value constellations. Proceedings of ICIS 2011, the 32nd International Conference on Information Systems.

Alter, S. (2011b). Reconciling the social/human and technical/material in IS research without trying too hard. SIGPhil Workshop on Reconciling the Social and the Technical, ICIS 2011, Shanghai, China.

Alter, S. (2012a). Genuinely service-oriented enterprises: Using work system theory to see beyond the promise of efficient software architecture. Proceedings of AMCIS 2012, the Eighteenth Americas Conference on Information Systems, Seattle, Washington.

Alter, S. (2012b). Metamodel for service analysis and design based on an operational view of service and service systems. Service Science, 4(3), 218-235.

Alter, S. (2012c). Resources for action: A detailed view of resources in service systems. Manuscript submitted for publication.

Alter, S. (2012d). System interaction theory. Manuscript submitted for publication.

Alter, S. (2012e). The knowledge cube: Scaffolding for a body of knowledge about information systems. Proceedings of ECIS 2012, the 20th European Conference on Information Systems.

Alter, S. (2012f). Theory of workarounds. Manuscript submitted for publication.

Alter, S. \& Bolloju, N. (2012). A work system front end for object-oriented analysis and design. Proceedings of the 11th Annual Symposium on Research in Systems Analysis and Design, Vancouver, Canada.

Alter, S., Bolloju, N., \& Vogel, D. (2009). Linking work system analysis and technical analysis using a conceptual model underlying the work system framework. Proceedings of WITS, 19th Workshop on Information Technologies and Systems, Phoenix, AZ, 19-24.

Alter, S., \& Wright, R. (2010). Validating work system principles for use in systems analysis and design. Proceedings of ICIS 2010, the 31st International Conference on Information Systems.

Appan, R., \& Browne, G. J. (2012). The impact of analyst-induced misinformation on the requirements elicitation process. MIS Quarterly, 36(1), 85-106.

Ashby, W. R. (1956). An introduction to cybernetics. Taylor \& Francis.

Avison, D. E., Wood-Harper, A. T., Vidgen, R. T., \& Wood, J. R. G. (1998). A further exploration into information systems development: The evolution of Multiview2. Information Technology \& People, 11(2), 124-139

Bacon, J., \& Fitzgerald, B. (2001). A systemic framework for the field of information systems. Database, 32(2), 46-67.

Barki, H., Rivard, S., \& Talbot, J. (1988). An information systems keyword classification scheme. MIS Quarterly, 12(2), 299-322.

Baskerville, R. (2011). Design theorizing individual information systems. Proceedings of PACIS 2011.

Beekhuyzen, J. P. (2009). A critical ethnography of an online file sharing community: An actornetwork theory perspective of controversies in the digital music world (Doctoral Dissertation). Griffith University, Brisbane, Australia.

Beer, S. (1981). Brain of the firm ( $2^{\text {nd }}$ Ed.). New York: John Wiley. 
Benbasat, I., \& Zmud, R. W. (2003). The identity crisis within the IS discipline: Defining and communicating the discipline's core properties. MIS Quarterly, 27(2), 183-194

Benbasat, I., \& Zmud, R. W. (2006). Further reflections on the identity crisis. In J. L. King and K. Lyytinen (Eds.), Information systems: The state of the field (pp. 300-306). Chichester, England: John Wiley \& Sons, Ltd.

BenMoussa, C. (2007). Mobile information and communication technology in the context of pharmaceutical sales force work. Proceedings of the 40th Hawaii International Conference on System Sciences.

BenMoussa, C. (2010). Exploiting mobile technologies to build a knowledge mobilization capability: A work system-based method. Proceedings of the 43rd Hawaii International Conference on System Sciences.

Beverungen, D., Wittchen, M., \& Becker, J. (2011). Where are the participants? Including motivational aspects into theorizing and design in IS research. Proceedings of the European Conference on Information Systems.

Bostrom, R. P., \& Heinen, J. S. (1977a). MIS problems and failures: A socio-technical perspective. Part I: The causes. MIS Quarterly, 1(3), 17-32.

Bostrom, R. P., \& Heinen, J. S. (1977b). MIS Problems and failures: A socio-technical perspective. Part II: The application of socio-technical theory. MIS Quarterly, 1(4), 11-28.

Boulding, K. (1964). General systems as a point of view. In J. Mesarovic, Views on general systems theory. New York: John Wiley.

Brown, A. W., Delbaere, M., Eeles, P., Johnston, S., \& Weaver, R. (2005). Realizing service-oriented solutions with the IBM rational software development platform. IBM Systems Journal, 44(4), 727-752.

Brynjolfsson, E. (2003, July). The IT productivity gap. Optimize Magazine. Retrieved 4 April, 2012, from http://ebusiness.mit.edu/erik/Optimize/pr_roi.html

Brynjolfsson, E., \& Saunders, A. (2010). Wired for innovation: How Information technology is reshaping the economy. Cambridge, MA: MIT Press.

Byrd, T. A., Cossick, K. L., \& Zmud, R. W. (1992). A synthesis of research on requirements analysis and knowledge acquisition techniques. MIS Quarterly, 16(1), 117-138.

Callon, M. (1986). Some elements of a sociology of translation: Domestication of the scallops and the fishermen of saint brieuc bay. In J. Law (Ed.) Power, action and belief: A new sociology of knowledge? (pp. 196-233). London: Routledge.

Cecez-Kecmanovic, D., Galliers, B., Henfridsson, O., Newell, S., \& Vigden, R. (2010). On sociomateriality of information systems and organizing (call for papers). MIS Quarterly. Retrieved from http://www.misq.org/skin/frontend/default/misq/pdf/CurrentCalls/ SI_Sociomateriality.pdf

Checkland, P. (1999). Systems thinking, systems practice. Chichester, UK: John Wiley \& Sons.

Cherns, A. (1976). Principles of socio-technical design. Human Relations, 2(9), 783-792.

Chesbrough, H., \& Spohrer, J. (2006). A research manifesto for services science. Communications of the $A C M, 49(7), 35-40$.

Ciborra, C. (1999). Notes on improvisation and time in organizations. Accounting, Management and Information Technologies, 9(2), 77-94.

Ciborra, C. (2002). The Labyrinths of information: Challenging the wisdom of systems. Oxford, UK: Oxford University Press.

Chesbrough, H., \& Spohrer, J. (2006). A research manifesto for services science. Communications of the ACM, 49(7), 35-40.

Churchman, C. W. (1979). The design of inquiring systems: Basic concepts of systems and organizations. New York, Basic Books

Clarke, K. A., \& Primo, D. M. (2012, April 1). Overcoming "physics envy". The New York Times.

Crowston, K., Howison, J., \& Rubleske, J. (2006). Coordination theory: A ten year retrospective. In P. Zhang \& D. Galletta, D. (Eds.), Human-computer interaction in management information systems - foundations (pp. 120-138). Armonk, NY: M. E. Sharpe, Inc.

Cuellar, M. J., McLean, E. R., \& Johnson, R. D. (2006). The measurement of information system use: preliminary considerations. Proceedings of the 2006 ACM SIGMIS CPR, Conference on Computer Personnel Research, 164-168. 
Cuellar, M. (2010). Assessing project success: Moving beyond the triple constraint. International Research Workshop on IT Project Management 2010.

Curtin, J., Kauffman, R. J., \& Riggins, F. J. (2007). Making the "most" out of RFID technology: A research agenda for the study of the adoption, usage, and impact of RFID. Information Technology and Management, 8(2), 87-110.

Davamanirajan, P., Kauffman, R. J., Kriebel, C. H., \& Mukhopadhyay, T. (2006). Systems design, process performance, and economic outcomes. Proceedings of the $39^{\text {th }}$ Hawaii International Conference on System Sciences.

Davis, L. E., \& Taylor, J. C. (Eds.) (1979). Design of jobs ( $2^{\text {nd }}$ Ed.). Santa Monica, CA: Goodyear Publishing Company.

Davison, R. M., Ou, C. X. J., Li, M. Y., Martinsons, M. G., \& Bjorksten, J. (2008). The multimethodological investigation of knowledge sharing practices in Eastwei. Proceedings of ICIS 2008.

DeLone, W. H., \& McLean, E. R. (1992). Information systems success: The quest for the dependent variable. Information Systems Research, 3(1), 60-95.

Delone, W. H., \& McLean, E. R. (2002). Information systems success revisited. Proceedings of the 35th Annual Hawaii International Conference on System Sciences. IEEE.

Demirkan, H., \& Goul, M. (2006). AMCIS 2006 panel summary: Towards the service oriented enterprise vision: Bridging industry and academics. Communications of the Association for Information Systems, 18(1), 546-556.

Dennis, A., Wixom, B. H., \& Roth, R. M. (2009). Systems analysis \& design with UML version 2.0: An object-oriented approach ( $3^{\text {rd }}$ Ed.). New York, NY: John Wiley \& Sons, Inc.

Dobing, B., \& Parsons, J. (2006). How UML is used. Communications of the ACM, 49(5), 109-113.

Dobing, B., \& Parsons, J. (2008). Dimensions of UML diagram use: A survey of practitioners. Journal of Database Management, 19(1), 1-18.

Efeoglu, A., Gong, A. J., Kristoffersen, J. M., Juul, S., Winter, R., Pries-Heje, L., \& Møller, C. (2012). Design science research in enterprise information systems. In C. Møller \& S. Chaudhury (Eds.), Advances in enterprise information systems II (pp. 191-203). London, UK: Taylor and Francis Group.

Elmaallam, M., \& Kriouile, A. (2012). A model of maturity for IS risk management case study. Computer and Information Science, 5(3), 97-109.

Engeström, Y. (1990) Learning, working, and imagining: Twelve studies in activity theory. Helsinki: Orienta-Konsultit Oy.

Feldman, M. S., \& Pentland, B. T. (2003). Re-theorizing organizational routines as a source of flexibility and change. Administrative Science Quarterly, 48, 94-118.

Feldman, M., \& Orlikowski, W. (2011). Theorizing practice and practicing theory. Organization Science, 22(5), 1240-1253.

Ferrario, R., Guarino, N., Trampus, R., Laskey, K., Hartman, A., \& Gangadharan, G. R. (2012) Service system approaches: Conceptual modeling approaches for services science. In A. Barros \& D. Oberle (Eds.), Handbook of service description: UDSL and its methods (pp. 75 109). New York, NY: Springer Science-Business Media.

Forrester, J. (1971). Counterintuitive behavior of social systems. Technology Review, 73(3), 52-68.

Gericke, A. \& Winter, R. (2009). On the application of the ISD method engineering approach to organizational engineering. IWODE09 - International Workshop on Organizational Design and Engineering.

Germonprez, M., Hovorka, D., \& Gal, U. (2011). Secondary design: A case of behavior design science research. Journal of the Association for Information Systems, 12(10), 662-683.

Giddens, A. (1984). The constitution of society. Berkeley, CA: University of California Press.

Goldschmidt, P., Joseph, P., \& Debowski, S. (2012). Designing an effective EDRMS based on Alter's service work system model. Records Management Journal, 22(3).

Goldstein, J.C. (2009). Information technology-related operational risk: An empirical study (Doctoral dissertation). University of Syracuse, USA.

Goodhue, D. L. (2007). Comment on Benbasat and Barki's 'Quo Vadis TAM' article. Journal of the Association for Information Systems, 8(4), 219-222. 
Granlien, M. S. (2010). Participation and evaluation in the design of healthcare work systems - a participatory design approach to organisational implementation (Doctoral dissertation). Roskilde University, Roskilde, Denmark.

Graves, T. (2009). The service-oriented enterprise: Enterprise architecture and viable services. Colchester, England: Tetradian Books.

Gray, P. (2006). Manager's guide to making decisions about information systems. Hoboken, NJ: John Wiley \& Sons.

Gregor, S. (2006). The nature of theory in information systems. MIS Quarterly, 30(3), 611-642.

Gregor, S., \& Jones, D. (2007). The anatomy of a design theory. Journal of the Association for Information Systems, 8(5), 312-335.

Gregor, S., \& Hevner, A. R. (2011). Introduction to the special issue on design science. Information Systems and E-Business Management, 9, 1-9.

Gregory, M. \& Descubes, I. (2011). Structured reflection in information systems teaching and research. Proceedings of the UK Academy for Information Systems Conference.

Grgecic, D. (2011). Applying structuration theory to investigate business process change. Proceedings of the 44th Hawaii International Conference on System Sciences, Kauai, Hawaii, USA.

Grover, V., Lyytinen, K., Srinivasan, A., Tan, B. C. Y. (2008). Contributing to rigorous and forward thinking explanatory theory. Journal of the Association for Information Systems, 9(2), 40-47.

Hall, J. M., \& Johnson, M. E. (2009). When should a process be art? Harvard Business Review, $87(3), 58-64$

Hassan, N., \& Mathiassen, L. (2009). Combining Scientometric and Content Analysis Methods for Identifying Core Concepts and Action Principles of Information Systems Development, Proceedings of the Fifteenth Americas Conference on Information Systems, San Francisco, $C A$.

Hevner, A., March, S. T., Park, J., \& Ram, S. (2004). Design science in information systems research. MIS Quarterly, 28(1), 75-105.

Hill, C., Yates, R., Jones, C., \& Kogan, S. L. (2006). Beyond predictable workflows: Enhancing productivity in artful business processes. IBM Systems Journal, 45(4), 663-682.

Hirschheim, R., \& Klein, H. K. (1994). Realizing emancipatory principles in information systems development: The case for ETHICS. MIS Quarterly, 18(1), 83-109.

Hirschheim, R., \& Klein, H. K. (2003). Crisis in the IS field? A critical reflection on the state of the discipline. Journal of the Association for Information Systems, 4(5), 237-293.

Hoermann, S., Schermann, M., \& Krcmar, H. (2011). When to manage risks in IS projects: An exploratory analysis of longitudinal risk reports. Proceedings of the 10th International Conference on Wirtschaftsinformatik, Zurich, Switzerland.

Hosack, B., Hall, D., Paradice, D., \& Courtney, J. F. (2012). A look toward the future: Decision support systems research is alive and well. Journal of the Association for Information Systems, 13, 315-340.

livari J. (2007). A paradigmatic analysis of information systems as a design science. Scandinavian Journal of information Systems, 19(2), 39-64.

livari, J., Hirschheim, R. A., \& Klein, H. K. (2004). Towards a distinctive body of knowledge for information systems experts: Coding ISD process knowledge in two IS journals. Information Systems Journal, 14, 313-342.

Islam, N., Akter, M., Kashem, M. A., \& Rahman, M. (2011). An efficient and speedy activity model for information system based organizations. Global Journal of Computer Science and Technology, 11(22), 52-58.

Jasperson, J., Carter, P. E., \& Zmud, R. W. (2005). A comprehensive conceptualization of postadoptive behaviors associated with information technology enabled work systems. MIS Quarterly, 29(3), 525-557

Kaakaanpää, I. (2011). IT artefact renewal: Triggers, timing and benefits (Doctoral dissertation). University of Jyväskylä, Finland.

Kampath, N., \& Röglinger, M. (2010). Operational and work system-related success factors for customer relationship management in "product sales" and "solution sales" - a descriptive case study. Proceedings of ECIS 2010, the 18th European Conference on Information Systems. 
Kaptelinin, V., \& Nardi, B. E. (2006). Acting With technology: Activity theory and interaction theory. Cambridge: MIT Press.

Kendall, K. E., \& Kendall, J. E. (2011). Systems analysis and design $\left(8^{\text {th }}\right.$ Ed.). Upper Saddle River, NJ: Pearson Prentice Hall.

Kizior, R.J. (2001). The Constant Evolution of an Introductory Information System Course: A Course in Flux. Proceedings of ISECON 2001.

Kosaka, T. (2008). Systems analysts in chaordic organizations. Proceedings of the Mediterranean Conference on Information Systems.

Kosaka, T. (2009). Basis of systems analysis method for business professionals. Proceedings of the International Association for the Development of the Information Society, Barcelona, Spain.

Kurpjuweit, S., \& Winter, R. (2007). Viewpoint-based meta model engineering. In M. Reichert, S. Strecker, \& K. Turowski (Eds.), Proceedings of the 2nd International Workshop on Enterprise Modelling and Information Systems Architectures (pp.143-161). St. Goar, Germany.

Lafaye, C. (2009). Intelligent agent appropriation in the tracking phase of an environmental scanning process: A case study of a French trade union. Information Research, 14(1). http://informationr.net/ir/14-1/paper390.html

Lamb, R., \& Kling, R. (2003). Reconceptualizing users as social actors in information system research. MIS Quarterly, 27(2), 197-235.

Lawrence, R. J. (2011). A comparison of the DeLone and McLean model of IS Success and the work system method: Three field studies in healthcare organizations (Doctoral dissertation). Texas Tech University, USA.

Lee, A.S. (2010). Retrospect and prospect: Information systems research in the last and next 25 years. Journal of Information Technology, 25, 336-348.

Lemey, E., \& Poels, G (2012a). Towards a process model for service systems. Exploring Services Science: Third International Conference, IESS 2012, Geneva, Switzerland, February 15-17, 2012, Proceedings, 1-15, Berlin: Springer.

Lemey, E., \& Poels, G. (2012b). Towards a service system ontology for service science. Proceedings of the 9th International Conference on Service-Oriented Computing Paphos, Cyprus, 250264.

Litchfield, A. T. M. (2011). The semantics of work in a work system: A pragmatic philosophy of information systems (Doctoral dissertation). Auckland University of Technology, New Zealand.

Luukkonen, I., Korpela, M., \& Mykkänen, J. (2010). Modelling approaches in the early phases of information systems development. Proceedings of the 18th European Conference on Information Systems.

Lyytinen, K., \& King, J. (2004). Nothing at the center?: Academic legitimacy in the information systems field. Journal of the Association for Information Systems, 5(6), 220-246.

Lyytinen, K., \& Newman, M. (2008). Explaining information system change: A punctuated sociotechnical change model. European Journal of Information Systems, 17, 589-613.

Madsen, S., \& Vigden, R. (2009). A pragmatic approach to IS development and socio-technical evaluation. Proceedings of the 17th European Conference on Information Systems

Majchrzak, A., \& Borys, B. (2001). Generating testable socio-technical systems theory. Journal of Engineering Technology and Management, 1105, 1-22.

Majchrzak, A., \& Gasser, L. (2000). TOP modeler. Information, Knowledge, \& System Management, 2(1), 95-110.

Malone, T. W., Crowston, K., Lee, J., Pentland, B., Dellarocas, C., Wyner, G., Quimby, J., Osborn, C. S., Bernstein, A., Herman, G., Klein, M., \& O'Donnell, E. (1999). Tools for inventing organizations: Toward a handbook of organizational processes. Management Science, 45(3), 425-443.

March S., \& Smith, G. (1995). Design and natural science research on information technology. Decision Support Systems, 15, 251-266.

Markus, M. L., Majchrzak, A., \& Gasser, L. (2002). A design theory for systems that support emergent knowledge processes. MIS Quarterly, 26(3), 179-212.

Markus, M. L., \& Mao, J. -Y. (2004). Participation in development and implementation - updating an old, tired concept for today's IS contexts. Journal of the Association for Information Systems, 5(11), 514-544. 
Markus, M. L., \& Robey, D. (1988). Information technology and organizational change: Causal structure in theory and research. Management Science, 34(5), 583-598.

Markus, M. L., \& Silver, M. S. (2008). A foundation for the study of IT effects: A new look at DeSanctis and Poole's concepts of structural features and spirit. Journal of the Association of Information Systems, 9(10/11), 609-632.

Mathiassen, L., Munk-Madsen, A., Neilsen, P. A., \& Stage, J. (2000). Object oriented analysis \& design. Aalborg, Denmark: Marko Publishing ApS.

Mettler, T. (2009). Towards a maturity model for supplier relationship management of hospitals. Proceedings of the 16th European Conference on Information Systems.

Miller, J. G. (1978). Living systems. New York: McGraw-Hill.

Mingers, J., \& White, L. (2010). A review of the recent contribution of systems thinking to operational research and management science. European Journal of Operational Research, 207(3), $1147-1161$.

Misra, R. B., Petkov, D., \& Petkova, O. (2009). Research directions in incorporating work system method ideas in systems analysis and design. In Y. K. Dwivedi, B. Lai, K. D. Williams, S. L. Schneberger, \& M. Wade (Eds.), Handbook of research on contemporary theoretical models in information systems (pp. 131-140). Hershey, PA: IGI Global.

Mitchell, V. L., \& Zmud, R. W. (1999). The effects of coupling IT and work process strategy in redesign projects. Organization Science, 4(10), 424-438.

Møller, C. (2006). The conceptual framework for business process innovation (Working Paper No. 12006-02). Informatics Research Group, Aarhus School of Business, Denmark. Retrieved from http://www.hha.dk/bs/wp/inf/I_2006_02.pdfMumford, E., \& Weir, M. (1979). Computer systems in work design - the ETHICS method. New York: John Wiley \& Sons.

Mumford, E., (2000). Socio-technical Design: An Unfulfilled Promise? Proceedings of IFIP W.G.8.2 Working Conference 2000 (pp. 33-46). In R. Baskerville, J. Stage, \& J. I. DeGross (Eds.), Organizational and social perspectives on information technology (Vol. 41). Springer.

Normann, R., \& Ramirez, R. (1994). Designing interactive strategy: From value chain to value constellation. Chichester, UK: John Wiley \& Sons.

Nunamaker J., Chen M., \& Purdin T. (1990-91). Systems development in information systems research. Journal of Management Information Systems, 7(3), 89-106.

Oinas-Kukkonen, H. (2010). The discipline of information systems: A natural strategic alliance for web science. Web Science Conference, Raleigh, NC, USA.

Orlikowski, W. J., \& Scott, S. V. (2008). Sociomateriality: Challenging the separation of technology, work and organization. Academy of Management Annals, 2(1), 433-474.

Orton, J. D., \& Weick, K. E. (1990). Loosely coupled systems: A reconceptualization. The Academy of Management Review, 15(2), 203-223.

Ou, C. X., \& Banerjee, P. K. (2009). Determinants of successful customer relationship management. Journal of Information Technology Management, 20(1), 56-66.

Panko, R. (2012). Rethinking "systems" in information systems (systematically). Proceedings of the European Conference on Information Systems.

Pasmore, W. A. (1985). Social science transformer: The socio-technical perspective. Human Relations, 48(1), 1-22.

Peng, Y. (2012). Modelling and designing IT-enabled service systems driven by requirements and collaboration (Doctoral dissertation). L'institut national des sciences appliquées de Lyon.

Pentland, B. T., Haerem, T., \& Hillison, D. (2011). The (N)Ever-changing world: Stability and change in organizational routines. Organization Science, 22(6), 1360-1383.

Petersson, J. (2008). Work system principles: Towards a justified design theory on the grounds of socio-instrumental pragmatism. In Proceedings of the 3rd international conference on the pragmatic web: Innovating the interactive society, 69-76.

Petkov, D., \& Petkova, O. (2008). The work system model as a tool for understanding the problem in an introductory IS project. Information Systems Education Journal, 6(21), 1-12.

Petkov, D., \& Petkova, O. (2010). An exploratory study on the student acceptance of the work system method as part of the systems analysis and design course. Proceedings of Information Systems Educators Conference, Nashville, TN. 
Petkov, D., Petkova, O., Sewchurran, K. Andrew, T., \& Misra, R. (2012). The work system method as an approach for teaching and researching information systems. In Y. K. Dwivedi, M. R. Wade, \& S. L. Schneberger (Eds.), Information systems theory: Explaining and predicting our digital society (pp. 413-424). New York: Springer.

Petrie, D. E. (2004). Understanding the impact of technological discontinuities on information systems management: The case of business-to-business electronic commerce (Doctoral dissertation). Claremont Graduate University, Claremont.

Pinhanez, C. (2009). "Users inside" as the key characteristic of service systems. Proceedings of QUIS'11, Wolfsburg, Germany.

Ralph, P., \& Wand, Y. (2009). A proposal for a formal definition of the design concept. In K. J. Lyytinen, P. Loucopoulos, J. Mylopoulos, \& W. Robinson (Eds.), Design requirements engineering: A ten-year perspective (pp. 102-137). Berlin: Springer.

Ramiller, N. (2002). Animating the concept of business process in the core course in information systems. Journal of Informatics Education and Research, 3(2), 53-71.

Re, B. (2010). Quality of (digital) services in e-government (Doctoral dissertation). Universita degli Studi di Camerino.

Recker, J. C. (2010). Opportunities and constraints: The current struggle with BPMN. Business Process Management Journal, 16(1), 181-201.

Recker, J. C., \& Alter, S. (2012). Using the work system method with freshman information system students. Journal of Information Technology Education: Innovations in Practice, 11, 1-24.

Roelens, B., Lemey, E., \& Poels, G. (2012). A service science perspective on business modeling. Proceedings of the 6th International Workshop on Value Modeling and Business Ontology.

Rose, J., Jones, M. R., \& Truex, D. (2005). Socio-theoretic accounts of IS: The problem of agency. Scandinavian Journal of Information Systems, 17(1), 133-152.

Schatzki, T. R. (2001). Practice theory. In T. R. Schatzki, K. Knorr Cetina, \& E. von Savigny (Eds.), The practice turn in contemporary theory (pp. 1-14). London: Routledge.

Scheepers, R., Davis, H., Sonenberg, L., \& Howard, S. (2011). Consumer health ICT and the patient in the middle: Adopter and/or influencer? Proceedings of the Pacific Asia Conference on Information Systems.

Schmidt, K., \& Bannon, L. (1992). Taking CSCW seriously: Supporting articulation work. Computer Supported Cooperative Work, 1(1), 7-40.

Schneberger, S., \& Wade, M. (Eds.). (2012). Theories used in IS research wiki. Retrieved April 6, 2012 from http://istheory.byu.edu/wiki/Main_Page

Sein, M. K., Henfridsson, O., Purao, S., Rossi, M., \& Lindgren, R. (2011). Action design research. MIS Quarterly, 35(1), 37-56.

Sewchurran, K., \& Petkov, D. (2007). A systematic framework for business process modeling combining soft systems methodology and UML. Information Resources Management Journal, 20(3), 46-62

Sherer, S., \& Alter, S. (2004). Information system risks and risk factors: Are they mostly about information systems? Communications of the Association for Information Systems, 14(2), 2964.

Siau, K., Erickson, J., \& Lee, L. (2005). Theoretical versus practical complexity: The case of UML. Journal of Database Management, 16(3), 40-57.

Singh, S. N., \& Woo, C. (2008). A methodology for discovering goals at different organizational levels. Proceedings of Third International Workshop on Business/IT Alignment and Interoperability, Montpelier, France.

Sinisammal, J., Belt, P., Härkönen, J. Möttönen, M., \& Väyrynen, S. (2012). Managing well-being at work during 2010 s - expert viewpoints. Open Journal of Safety Science and Technology, 2, 25-31.

Skyttner, L. (1996). General systems theory: Origin and hallmarks. Kybernetes, 25(6), 16-22.

Skyttner, L. (2005). General systems theory: Problems, perspectives, practice. Singapore: World Scientific Publishing.

Sobyanina, E., \& Mockutè,I. (2011). ERP post-implementation: Risk assessment (Masters thesis). Mälardalen University, Sweden

Spohrer, J., Maglio, P. P., Bailey, J., Gruhl, D. (2007). Steps toward a science of service systems. IEEE Computer, 40(1), 71-77. 
Srinivasan, A., March, S., \& Saunders, C. (2005). Information technology and organizational contexts: Orienting our work along key dimensions. Proceedings of the Twenty-Sixth International Conference on Information Systems.

Star, S. L., \& Strauss, A. L. (1999). Layers of silence, arenas of voice: The ecology of visible and invisible work. Computer-Supported Cooperative Work (CSCW). The Journal of Collaborative Computing, 8, 9-30.

Star, S. L., \& Bowker, G. C. (2002). How to Infrastructure. In L. Lievrouw \& S. Livingstone (Eds.), Handbook of the new mediai (pp. 151-162). London: SAGE.

Stowell, F. A., \& West, D. (1995). Client-led design. Maidenhead, UK: McGraw-Hill.

Suchman, L. (1987). Plans and situated actions: The problem of human-machine communication. Cambridge, UK: Cambridge University Press

Sumner, M., \& Ryan, T. (1994). The impact of CASE: Can it achieve critical success factors? Journal of Systems Management, 45(6), 16-22.

Sutton, R. I., \& Staw, B. M. (1995). What theory is not. Administrative Sciences Quarterly, 40(3), 371-384.

Tan, X., Alter, S., \& Siau, K. (2011). Using service responsibility tables to supplement UML in analyzing e-service systems. Decision Support Systems, 51(3), 350-360.

Thomas, D. M., Gupta, S., \& Bostrom, R. P. (2008). A meta-theory for understanding IS in sociotechnical systems. Proceedings of the 41st Hawaii International Conference on System Sciences.

Trist, E. (1981). The evolution of socio-technical systems: A conceptual framework and an action research program. In V. de Ven \& W. Joyce (Eds.), Perspectives on Organizational Design and Behavior (pp. 19-75). NY: Wiley Interscience.

Truex, D. P., Baskerville, R., \& Travis, J. (2000). Amethodical systems development: The deferred meaning of systems development methods. Accounting Management and Information Technologies, 10, 53-79.

Truex, D., Alter, S., \& Long, C. (2010). Systems analysis for everyone else: Empowering business professionals through a systems analysis method that fits their needs. Proceedings of 18th European Conference on Information Systems, Pretoria, South Africa.

Truex., D., Lakew, N., Alter, S., \& Sarkar, S. (2011). Extending a systems analysis method for business professionals. European Design Science Symposium, Leixlip, Ireland.

Tyre, M. J., \& Orlikowski, W. J. (1994). Windows of opportunity: Temporal patterns of technological adaptation in organizations. Organization Science, 5(1), 98-118.

Valacich, J. S., George, J. F., \& Hoffer, J. A. (2012). Essentials of systems analysis and design ( $5^{\text {th }}$ Ed.). Upper Saddle River, NJ: Pearson Prentice Hall.

Valkonen, M. (2011). Change management in a software project from the perspective of a software company (Masters thesis). Tampere University of Technology.

van der Aalst, W., ter Hofstede A., \& Weske M. (2003). Business process management: A survey. In W. van der Aalst, A. ter Hofstede, \& M. Weske (Eds.), International conference on business process management: Volume 2678. Lecture Notes in Computer Science (pp. 1-12). Springer Verlag, Berlin.

Vartiainen, T., Aramo-Immonen, H., Jussila, J., Pirhonen M., \& Liikamaa, K. (2011). replacement of the project manager reflected through activity theory and work-system theory. In W. W. Song, S. Xu, C. Wan, Y. Zhong, W. Wojtkowski, G. Wojtkowski, \& H. Linger (Eds.), Information systems development: Asian experiences (pp. 111-122). New York: Springer.

vom Brocke J., \& Rosemann, M. (Eds.) (2010). Handbook on business process management. Berlin: Springer.

Walls, J. G., Widemeyer, G. R., \& El Sawy, O. A. (1992). Building an information system design theory for vigilant EIS. Information Systems Research, 3(1), 36-59.

Wand, Y., \& Weber, R. (2002). Research commentary: Information systems and conceptual modeling - A research agenda. Information Systems Research, 13(4), 363-376.

Wastell, D. (2010). Managing as designing: "Opportunity knocks" for the IS field? European Journal of Information Systems, 19, 422-431.

Watson, R. (2001). Research in information systems: What we haven't learned. MIS Quarterly, 25(4), $\mathrm{V}-\mathrm{XV}$.

Weber, R. (2003). Editor's Comments. MIS Quarterly, 27(2), iii-xi. 
Weber, R. (2012). Evaluating and developing theories in the information systems discipline. Journal of the Association for Information Systems, 13(1), 1-30.

Weick, K. E. (1995). What theory is not, theorizing is. Administrative Sciences Quarterly, 40(3), 385-390. Weinberg, G. (1975). An introduction to general systems thinking. New York: John Wiley \& Sons.

Welke, R., Hirschheim, R., \& Schwarz, A. (2011). Service-oriented architecture maturity. IEEE Computer, 44(2), 61-67.

Wetherbe, J. (1991). Executive information requirements: Getting it right. MIS Quarterly, 15(1), 51-65.

Winter, R. (2010). Organisational design and engineering: Proposal of a conceptual framework and comparison of business engineering with other approaches. International Journal of Organisational Design and Engineering, 1(1/2), 126-147.

zur Muehlen, M., \& Recker, J. C. (2008). How much language is enough? theoretical and practical use of the business process modeling notation. Proceedings of the $20^{\text {th }}$ International conference on Advanced Information Systems Engineering, 465-479. 


\section{Appendices}

\section{Appendix 1. Different Versions of the Work System Method}

WSM has gone through a number of revisions over time, which also occurred with soft system methodology (Checkland, 1999), Multiview (Avison et al., 1998), and modeling languages such as UML and BPMN. Initial WSM versions emerged from the effort of writing, promoting, and using successive editions of an IS textbook (Alter, 1992, 1996, 1999b, 2002a), each of which was successively clearer about its emphasis on work systems.

WSM's initial development consciously adapted the type of approach that a product manager might use in developing ideas for product extension, and hence was quite different from the idealized, theory-motivated process sometimes proposed for creating artifacts using a design science research approach. The development started with a book tour that promoted the first edition of an information system textbook (Alter, 1992). The book tour included 22 presentations at universities and several research institutions. The presentations asked for feedback about the tentative content of a one hour lecture at a hypothetical business convention for business professionals from many different companies. Ideally, that lecture would be maximally helpful to convention attendees, each of whom was about be involved in a meeting for "reviewing an existing system, evaluating a proposal from a software vendor, or designing a new system" (Alter, 1996, p. iii). The basis of the presentations was a combination of prior years of experience in a software company and familiarity with the academic literature of that time. Feedback from the presentations helped in producing an initial systems analysis outline. Starting around 1995, MBA and Executive MBA students used successive versions of the outline to write group papers analyzing IT-reliant work systems in their own organizations. The papers from each semester revealed confusions, knowledge gaps, and other problems that led to revisions in the work system analysis outlines for subsequent semesters. Alter (2006a) discusses pitfalls observed in 202 group papers between 1997 and 2003 and identifies approaches that were attempted for minimizing those pitfalls. Other sources of improvements included examples from newspapers, the popular business press, and research journals that revealed omissions or confusions in a then-current version of the outline.

\section{The 1996 Version}

A precursor of WSM was "work-centered analysis" (WCA), which was presented at an international conference on IS concepts (Alter, 1995) and in the second edition of the IS textbook (Alter, 1996). With that approach, someone trying to analyze a system from a business viewpoint would use the WCA framework (the six central elements of the work system framework) as the basis for performing four steps organized around general problem solving: 1) determine the scope of the analysis, 2) describe the current situation, 3) design potential improvements, and 4) select among alternatives. The descriptions would use the following five perspectives to consider issues related to each of the elements of the WCA framework: architecture, performance, infrastructure, context, and risk. The third edition of the textbook (Alter, 1999b) clarified aspects of the WCA approach.

\section{The 2002 Version}

Because WCA seemed too complicated, the fourth edition (Alter, 2002a) replaced it with a "principlebased" systems analysis method that introduced current WSM terms such as work system, work system framework, and work system snapshot, and that applied seven general principles related to elements of the first version of the work system framework. Those principles were mentioned in Alter (2002a, 2002b), the first articles on WSM. Evaluations of MBA and Executive MBA reports using the principle-based initial version of WSM for several years led to the conclusion that highlighting only seven principles provided guidance that was too narrow in relation to the breadth of the problems and opportunities that should be addressed.

\section{The 2006 Version}

The 2006 version of WSM appeared for the first time in Alter (2006b). It is divided into three main steps that apply general problem solving to systems in organizations. Those three steps are: system and opportunity (SO), analysis and possibilities (AP), and recommendation and justification (RJ). 
- SO - Identify the System and Opportunities: Identify the work system that has the opportunities (or problems) that launched the analysis. The size and scope of the work system depends on the purpose of the analysis.

- AP - Analyze the system and identify Possibilities: Understand current issues and find possibilities for improving the work system.

- RJ - Recommend and Justify changes: Specify proposed changes and justify and sanitycheck the recommendation.

The 2006 version was designed for use in varied situations requiring different levels of detail and depth depending on the user's particular situation.

- Level one: Be sure to remember the three main steps (SO, AP, and RJ) when thinking about a system in an organization.

- Level two: In each main step, look at specific questions that are typically important.

- Level three: Drill down further to consider specific guidelines and concepts that are useful in certain situations.

Table 6 illustrates WSM's structure by showing how the level one summary of each of the three steps expands into more detailed questions at level two. The work system principles and work system design spaces mentioned earlier are examples of the types of topics that are included in level three.

\section{Table 6. First and Second Layers of Questions in the Work System Method as Defined in Alter} (2006b)

SO - Identify the System and Opportunities: What work system are we talking about? From a business viewpoint, what are opportunities and problems in this work system?

SO1: What are the problems or opportunities?

S02: What work system has these problems or opportunities?

S03: What factors contribute to problems or opportunities?

S04: What constraints limit the feasible range of recommendations?

SO5: Summarize the work system using a work system snapshot or a diagram.

AP - Analyze the system and identify Possibilities: What are the possibilities for improving this work system to address problems or opportunities related to each part of the work system?

AP1: Who are the customers and what are their concerns?

AP2: How good are the products and services produced by the work system?

AP3: How good are the work practices inside the work system?

AP4: How serious are any mismatches between the work system and the roles, knowledge, and interests of its participants?

AP5: How might better information or knowledge help?

AP6: How might better technology help?

AP7: How good is the work system's fit with its environment?

AP8: How well does the work system use the available infrastructure?

AP9: How appropriate is the work system's strategy?

AP10: How well does the work system operate as a whole? 
Table 6. First and Second Layers of Questions in the Work System Method as Defined in Alter (2006b) (cont.)

RJ - Recommend and Justify changes: What changes in the work system do we recommend and how could we justify those changes?

RJ1: What are the recommended changes to the work system?

RJ2: How does the preferred alternative compare to other alternatives?

RJ3: How does the recommended system compare to an ideal system in this area?

RJ4: How well do the recommended changes address the original problems and opportunities?

RJ5: What new problems or costs might be caused by the recommended changes?

RJ6: How well does the proposed work system conform to work system principles?

RJ7: How can the recommendations be implemented?

RJ8: How might perspectives or interests of different stakeholders influence the project's success?

RJ9: Are the recommended changes justified in terms of costs, benefits, and risks?

RJ10: Which important assumptions within the analysis and justification are most questionable?

The most basic level one application of WSM is a simple application of WST because it encourages the user to think about the situation in work system terms. It provides minimal guidance other than saying that each of the three main steps (SO, AP, and RJ) should be considered. For example, assume that several people are speaking in general about purported features and benefits of a CRM software package. Level one of WSM would encourage them to focus on the work system(s) that is being addressed rather than on the software. It would emphasize the work system's problems and opportunities, possibilities for improving the work system to address these problems or opportunities, and whatever changes in the work system should be recommended. Merely using these questions to stay focused on the work system instead of plunging into software details and features would probably make the initial discussion more productive and more directly related to whether the CRM addresses real business problems and opportunities in this setting. In discussions of this approach, several Executive MBA students said that paying attention to work systems in this way might have avoided expensive CRM disasters in their companies, which pursued CRM as a slogan rather than as a set of software capabilities to be incorporated into specific work systems.

The "SO" questions in level two help in defining the work system's scope, which is not known in advance, but rather, depends on the opportunities or problems that are being pursued. To expedite the analysis effort and focus the recommendations, the work system should be the smallest work system that has the opportunity or problem. Defining the work system and problem or opportunity together reduces the likelihood of focusing the analysis on the purported features and benefits of a vendor's software rather than on the business situation. WSM users frequently mention their surprise at the amount of thought and effort involved in identifying the work system and the opportunity or problem. Even when there is initial agreement about the work system's scope, looking at the situation in more depth as the analysis unfolds often leads to revising the initial assumptions about the work system's scope.

Although some of the "AP" questions in level two are more important than others in specific situations, inclusion of questions about all nine elements of the work system framework increases the likelihood that the analysis and design efforts will start with a reasonably balanced view of the work system and the range of possible improvements. In particular, this approach should overcome the common error of assuming that the system consists of little more than the software and computerized information.

The "RJ" questions at level two start by asking for a summary of the recommendation as a proposed "to-be" work system. To increase the likelihood of finding pitfalls and inconsistencies, level two calls for identifying changes related to each of the nine elements of the work system framework, not just the software and hardware. The ten RJ questions stress different issues that could reveal oversights or problems related to the recommendation's economic or organizational practicality. A business professional using the RJ questions might be able to answer only a subset of them. For example, it is rarely feasible to produce a cost-benefit justification without help from IT professionals who 
understand the technical issues and technical resources required. Nonetheless, the RJ questions can help in organizing an initial recommendation and justification, and can help in recognizing topics that need a deeper discussion and/or additional expertise.

\section{Recent Work System Analysis Template Outlining a Management Briefing and Separate Analysis}

Table 7 is outlines a work system analysis template used in BSIS, MSIS, and MBA courses in the Fall of 2011. This template encompasses topics in levels one and two of the 2006 version of WSM, plus some level three topics. To hide surface complexity, it emphasizes four analysis steps and does not refer to the levels or to the abbreviations SO, AP, and RJ. The template was designed to accomplish a dual pedagogical purpose. The effort of filling in the appendices provides experience in performing an organized, business-oriented analysis of a work system by defining the problem, summarizing the "asis" work system, looking at various aspects of the situation in more detail, and producing a justified recommendation summarizing the "to-be" work system. The effort of writing the management briefing reinforces the difference between performing the analysis and producing a management-oriented report related to the analysis and recommendation. Accordingly, the instructions to student users of the template were to fill in the appendices first and then to write the management briefing under the assumption that a decision maker may or may not look at the appendices. Consistent with the goal of supporting different levels of detail and completeness, the template for use by generalist MBA students in the context of a short course does not address some of the RJ questions. For example, it does not ask about conformance to work system principles (RJ6) or about justification of proposed changes in terms of costs and benefits (RJ9) that they do not have enough time to determine.

\section{Table 7. Summary of a Work System Analysis Template Used in Fall 2011}

Management briefing.

1. Executive summary

2. Background

3. System and problem

4. Analysis and possibilities

5. Recommendation and justification

1. Name of work system

2. Main problem or opportunity

Appendix 1: Initial summary of the existing work system and the problem or opportunity.

3. Significance of the work system

4. Constraints that limit the possible recommendations

5. Performance gaps related to processes, participants, information, or technology

6.Performance gaps related to customer perceptions of products/services

Appendix 2: Summary of the current ("as-is") work system and areas where customers perceive benefits from its operation and from its products/services.

1. Work system snapshot of the "as-is" work system

2. Customer value and customer concerns (for the primary customers)

3. Customer responsibilities (for the primary customers)

1. Problems, issues, and opportunities for the system as a whole 2. Problems, issues, and opportunities for each step in the processes or activities in the work system snapshot

Appendix 3. Summary of problems, issues, opportunities in the current ("as-is") service system.

3. Additional problems, issues, and opportunities for specific work system elements (e.g., participants, information)

4. Additional problems, issues, and opportunities related to specific types of activities within the work system (e.g., information processing, informing, communicating, social interaction, controlling work in order to achieve goals, decision making, and providing service)

Appendix 4: Summary of the 1. Work system snapshot of the "to-be" work system.

2. Likely impact of recommended changes for the system as a whole recommendations and their likely impacts.

3. Likely impact of recommended changes by step

4. Additional impacts of changes related to specific types of activities 


\section{Appendix 2. Position of Work System Theory in the IS Discipline}

The foregoing discussions of WST's core and its extensions provide a basis for positioning WST in relation to other aspects of the IS discipline that focus on systems in organizations. This positioning will be explained in two steps. Figure 3 places WST in the center of a "positioning framework" that identifies four groups of IS concepts and theories. Figure 4 uses a slightly modified version of Figure 3 to locate three components of WST, the work system concept, work system framework, and work system life cycle model, and a set of applications and extensions of WST that are associated with one or two of the groups of IS concepts and theories.

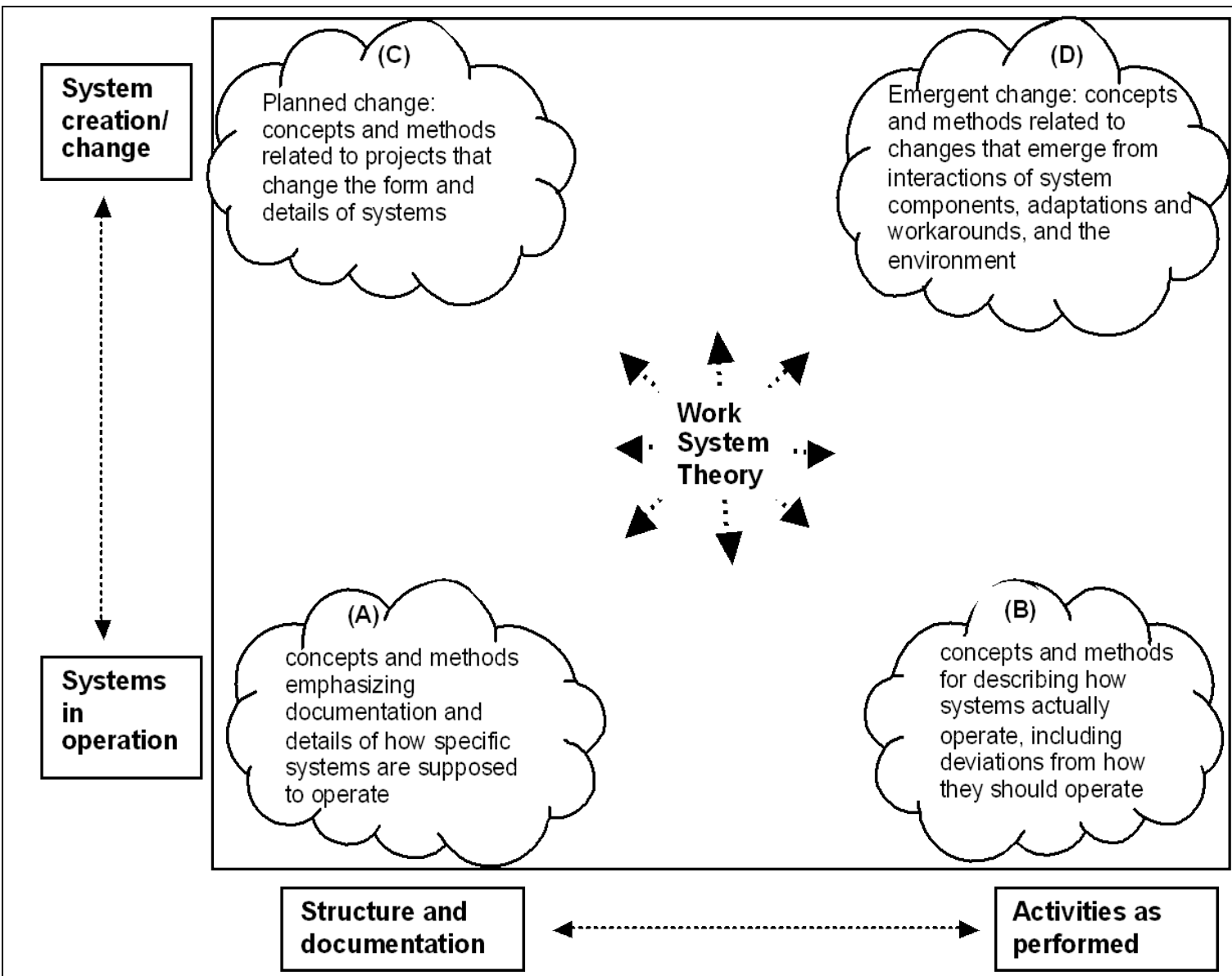

Examples of concepts and methods in each group:

- Group A: organization charts, flow charts, entity-relationship diagrams, UML, BPMN, enterprise architecture, conceptual modeling, structured and object-oriented analysis and design.

- Group B: organizational routines, business processes, technology-in-practice, workarounds, bricolage, adaptations, agency theory, structuration theory, social networks, practice theory, sociomateriality, ethnographic methods, action research, grounded theory.

- Group C: deliverable, milestone, work breakdown structure, waterfall development methods, agile development, project management, ERP implementation methods, business process reengineering,

- Group D: diffusion of innovation, adoption of technology, evolution of web-based services, organizational change, actor network theory, technological trends, societal trends related to use and impact of IT.

Figure 3. Position of WST in Relation to Other IS Concepts and Methods 


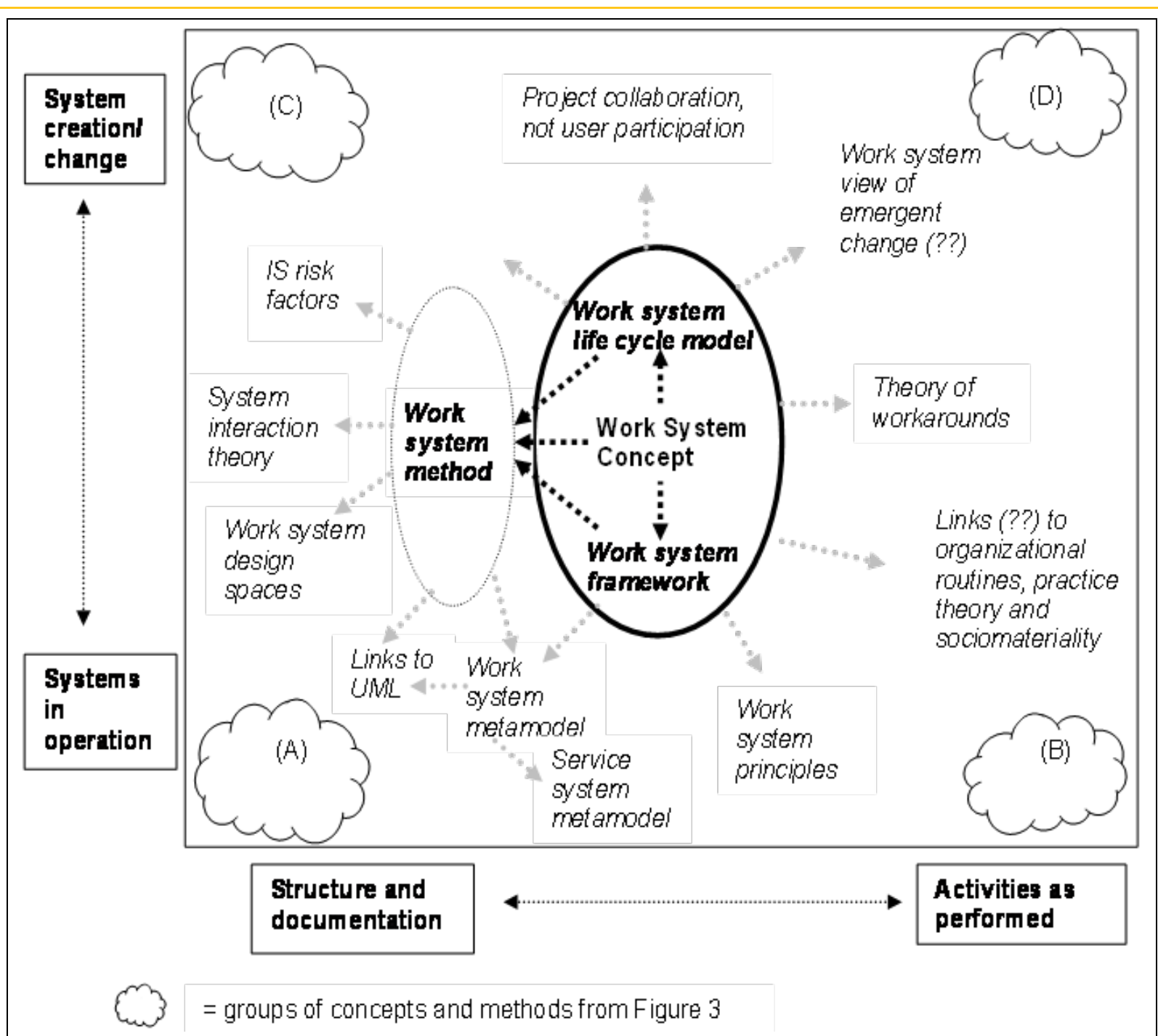

\section{Figure 4. Applications and Extensions of WST}

The location of WST in the center of Figure 3 and the outward directed arrows indicate that is related in various ways to concepts and methods in each of the four groups and may have applications or implications in many areas. The horizontal dimension in Figure 3 concerns the extent to which a concept or method is related to structure/ documentation versus being related to activities as actually performed. The vertical dimension concerns the extent to which a concept or method is related to systems in operation versus processes for creating or modifying systems. The groups of concepts and methods are placed inside cloud-like shapes instead of solidly bounded rectangles or ovals to emphasize that they are neither fixed nor impermeable. WST is in the middle because it looks at situations as work systems that have structure (group A) and usually are developed and modified through planned projects (group C) but that also may operate in ways that deviate from any formal structure (group B) and may change over time through emergent change processes (group D).

The representation of WST in Figure 3 reflects the way in which some of its value comes from extensions in response to issues and challenges that became evident as the core concepts were used. That type of expansion is not unique because many widely recognized ideas that initially were associated with one group of concepts and methods have expanded to include concepts and methods associated with other groups. A prime example is Six Sigma, which started as detailed statistical analysis of repetitive processes, a topic that belongs in group A. Current introductions to Six 
Sigma often describe it in relation broader models for planned change that belong in group $C$, such as DMAIC (define, measure, analyze, implement, control). Similarly, business process management (BPM) was associated with software for controlling workflows, a group A topic (e.g., van der Aalst, ter Hofstede, \& Weske, 2003), but has taken on broader meanings that also incorporate parts of group B related to managing processes and activities that actually occur in organizations (e.g., vom Brocke \& Rosemann, 2010).

Figure 4 builds on Figure 3. WST is represented by the central oval, in which arrows say that the work system concept led to the work system framework and work system life cycle model, all three of which have existed for over a decade and now can be seen as forming the conceptual basis of WSM. Figure 4 also shows more recent extensions that build upon those ideas. Placement of the WSTrelated topics in Figure 4 reflects their degree of association with the four groups of concepts and methods identified in Figure 3. Inside the primary oval, for example, the work system framework is closer to systems in operation and the WSLC is closer to system creation/ change. WSM is a direct application of WST and therefore is in a secondary oval whose placement shows that WSM combines aspects of systems in operation and system creation/ change. The other topics represent extensions of WST that are potentially valuable in various parts of the IS discipline. The light gray arrows indicate some of the directions in which extensions have occurred or may occur in the future.

As mentioned earlier, extensions of WST that addressed important gaps related to using WSM for analyzing and designing systems in organizations include work system principles, work system design spaces, and the work system metamodel. Starting near the top and going counterclockwise, other topics included in Figure 4 are listed below. Some of these topics were mentioned earlier in other contexts.

- Project collaboration, not user participation. Viewing IT-related projects as work system projects rather than IT projects generates a somewhat different perspective regarding "user participation" (Alter, 2009).

- IS risk factors. Many, perhaps a majority of risk factors that the IS literature associates with IS and IS projects are actually risk factors for work systems in general (Sherer \& Alter, 2004). Consequently, a deep understanding of IS risk factors starts with risk factors that apply to work systems in general.

- System interaction theory. The analysis and design of systems in organizations often should include interactions with other systems. Various types of direct, indirect, explicit, and implicit system interactions mentioned in Alter (2010c, 2012d) are not fully reflected in previous views of this type of issue, such as the three types of task interdependence (Thompson, 1967), coordination theory (Malone et al., 1999; Crowston, Howison, \& Rubleske, 2006), and loose coupling theory (Orton \& Weick, 1990).

- Links to UML. The work system metamodel provides a more detailed view of work systems than the work system framework, and therefore is more useful as a basis for converting from work system descriptions to certain types of UML diagrams (Alter \& Bolloju, 2012).

- Service system metamodel. The work system metamodel was expanded into a service system metamodel that encompasses additional ideas related to service and service systems (Alter, 2011a, 2012b).

- Links to organizational routines, practice theory, and sociomateriality. The idea of organizational routines overlaps in significant ways with ideas related to work systems and therefore seems to be an area of potential synergy with WST. It remains to be seen whether there will be synergy with more abstract topics related to organizational routines such as practice theory (Feldman \& Orlikowski, 2011) or sociomateriality (Orlikowski \& Scott, 2008). For example, it is possible that 
assumptions about the inherent inseparability between the technical and the social might provide an interesting analytical counterpoint to the more traditional approach expressed by the work system framework and work system metamodel.

- Theory of workarounds. A proposed theory of workarounds (Alter, 2012f) addresses issues related how workarounds emerge from the interaction of work system design, goals, incentives, obstacles, agency, monitoring systems, and other factors.

- Work system view of emergent change. The work system life cycle model includes both planned change and emergent change. It is possible that the underpinnings of the proposed theory of workarounds might provide a path toward a better articulated work system approach to emergent change.

The purpose of the above examples was to show that WST provides a fruitful starting point for looking at a large number of important topics. In most of these cases, one or several papers are basically initial steps that can be developed further. 


\section{About the Author}

Steven ALTER is Professor of Information Systems at the University of San Francisco. He converted his MIT Sloan Ph.D. thesis into one of the first books on decision support systems. He served for eight years as Vice President of Consilium, a manufacturing software firm that went public and was acquired by Applied Materials. His book, The work system method: Connecting people, processes, and IT for business results distilled and extended ideas in four previous editions of his information system textbook, which raised awareness of IT-reliant work systems. His long term research emphasis involves systems analysis concepts and methods that are usable by business professionals and can support communication with IT professionals. His recent research focuses on topics such as service systems, system interactions, workarounds, and links between work system analysis, UML/ BPMN, and enterprise engineering. His articles have been published in journals such as Harvard Business Review, Sloan Management Review, MIS Quarterly, IBM Systems Journal, European Journal of Information Systems, Decision Support Systems, Interfaces, Communications of the ACM, Communications of the AIS, CIO Insight, JITTA, and Service Science, and in many refereed conference proceedings. 